\title{
Estudo experimental de condicionamento ambiental com resfriamento evaporativo direto
}

\author{
Experimental study of environmental conditioning with \\ direct evaporative cooling
}

\section{Erico Masiero \\ Djanny Klismara Oliveira \\ Orlando Pereira da Costa \\ Francisco Arthur da Silva Vecchia}

\author{
Resumo \\ A
}

técnica de resfriamento evaporativo direto (RED) tem sido aplicada como alternativa ao condicionamento de ar por compressão para ambientes internos. O processo de RED consiste na redução da temperatura do ar pela evaporação da água. $\mathrm{O}$ objetivo deste estudo foi identificar o comportamento da temperatura, da umidade do ar e do consumo de água em uma célula-teste com uso de um equipamento eletromecânico de RED e comparar com as variações em uma célula de controle, sem qualquer sistema ativo de resfriamento. O consumo de água foi aferido de acordo com determinadas faixas de temperatura e umidade do ar externo. Os resultados mostraram que o período mais quente e mais seco do ar externo coincide com o momento em que o resfriador evaporativo atinge o ápice de seu desempenho, registrando $6,69^{\circ} \mathrm{C}$ de diferença entre as temperaturas interna e externa. No entanto, em períodos de clima quente e úmido, a diferença foi de apenas $1,74^{\circ} \mathrm{C}$. O consumo máximo de água registrado ao longo do experimento foi de $3,35 \mathrm{l} / \mathrm{h}$, considerando a temperatura do ar externo na faixa de $30^{\circ} \mathrm{C}$ e a umidade relativa do ar a $60 \%$. O estudo experimental fornece informações cruciais para a melhor adaptação do RED às edificações.

Palavras-chave: Resfriamento evaporativo direto. Psicrometria. Condicionamento térmico ambiental.

${ }^{1}$ Erico Masiero ${ }^{1}$ Universidade Federal de São Carlos São Carlos - SP - Brasil

${ }^{2}$ Djanny Klismara Oliveira ${ }^{2}$ Universidade Federal de São Carlos São Carlos - SP - Brasil

${ }^{3}$ Orlando Pereira da Costa ${ }^{3}$ Universidade Federal de São Carlos São Carlos - SP - Brasil

${ }^{4}$ Francisco Arthur da Silva Vecchia

4Universidade de São Paulo São Carlos - SP - Brasil

Recebido em 14/02/19 Aceito em 30/04/19

\section{Abstract}

The technique of direct evaporative cooling (DEC) has been applied as an alternative to air conditioning by compression for indoor environments. The DEC process consists of reducing air temperature by evaporating water. The aim of this study was to identify the behavior of temperature, air humidity and water consumption in a test cell using a DEC electromechanical equipment and to compare it with variations in a control test cell, without any active cooling system. Water consumption was measured according to certain temperature and humidity ranges of outside air. The results showed that the warmest and driest period of the external air coincides with the moment when the evaporative cooler reaches the peak of its performance, registering $6.69{ }^{\circ} \mathrm{C}$ of difference between the internal and external temperatures. However, in periods of warm and humid weather, the difference was only $1.74^{\circ} \mathrm{C}$. The maximum water consumption recorded during the experiment was $3.35 \mathrm{l} / \mathrm{h}$, considering the temperature of the outside air in the range of $30^{\circ} \mathrm{C}$ and the relative humidity at $60 \%$. The experimental study provides crucial information for the best adaptation of DEC to buildings.

Keywords: Direct evaporative cooling. Psychrometry. Environmental thermal conditioning.

MASIERO, E.; OLIVEIRA, D. K.; COSTA, O. P. da; VECCHIA, F. A. da S. Estudo experimental de condicionamento 


\section{Introdução}

O princípio físico da técnica de resfriamento evaporativo para condicionamento ambiental e obtenção de conforto térmico humano consiste em maximizar a evaporação de gotículas de água e favorecer seu contato com o ar ou com uma superfície (PEARLMUTTER et al., 1996; GIVONI, 1994, 1998; RORIZ; RORIZ, 2008; KRÜGER et al., 2016). Conforme o ar cede calor sensível, as gotículas de água passam do estado líquido para o gasoso, e como consequência do processo de transferência de calor sensível ocorre a evaporação da água. Assim, a temperatura do ar diminui e a umidade no interior de determinado ambiente aumenta de acordo com uma escala psicrométrica. Esse princípio de resfriamento evaporativo é usado de diversas maneiras em várias partes do mundo, muitas vezes de forma rudimentar, a fim de se obter conforto ambiental humano.

O exemplo mais familiar desse fenômeno, segundo Maurya, Shrivastav e Shrivastava (2014), é o resfriamento da superfície da pele humana pela transpiração, que resfria conforme a água do organismo é eliminada. Os autores relatam, inclusive, que o fenômeno pode funcionar de forma mais eficaz em ambientes quentes e secos, tornando o ar mais respirável. Segundo Watt e Brown (1997), quanto maior a diferença entre a temperatura de bulbo seco (TBS) e a temperatura de bulbo úmido (TBU) em um ambiente, maior será o efeito de resfriamento evaporativo.

O ábaco psicrométrico é uma ferramenta gráfica que simplifica a compreensão das relações entre a temperatura e a umidade do ar e informa como ocorrem as mudanças de estado físico da mistura de água do ar, conforme o exemplo da Figura 1. De forma genérica, a variação da TBS é disposta no eixo das abscissas, a taxa de umidade, no das ordenadas à direita, e, nas linhas diagonais, a TBU, a qual pode ser lida na linha curva à extrema esquerda da figura. Nas demais linhas curvas são plotados os valores de umidade relativa (UR), que correspondem à relação entre a TBS e a TBU. A linha-limite do ábaco psicrométrico, localizada à extrema esquerda da figura, indica que uma mistura de ar e água está saturada, ou seja, com $100 \%$ de umidade relativa (TORREIRA, 1976). Em outras palavras, em uma amostra de ar cuja TBS seja de $30^{\circ} \mathrm{C}$ no ponto 1 e a TBU de $20{ }^{\circ} \mathrm{C}$ a $40 \%$ de umidade relativa, ao receber certa quantidade de umidade, a TBS se reduz para $26{ }^{\circ} \mathrm{C}$ no ponto 2 , e a umidade relativa aumenta para $80 \%$.

\section{Figura 1 - Ábaco psicrométrico}

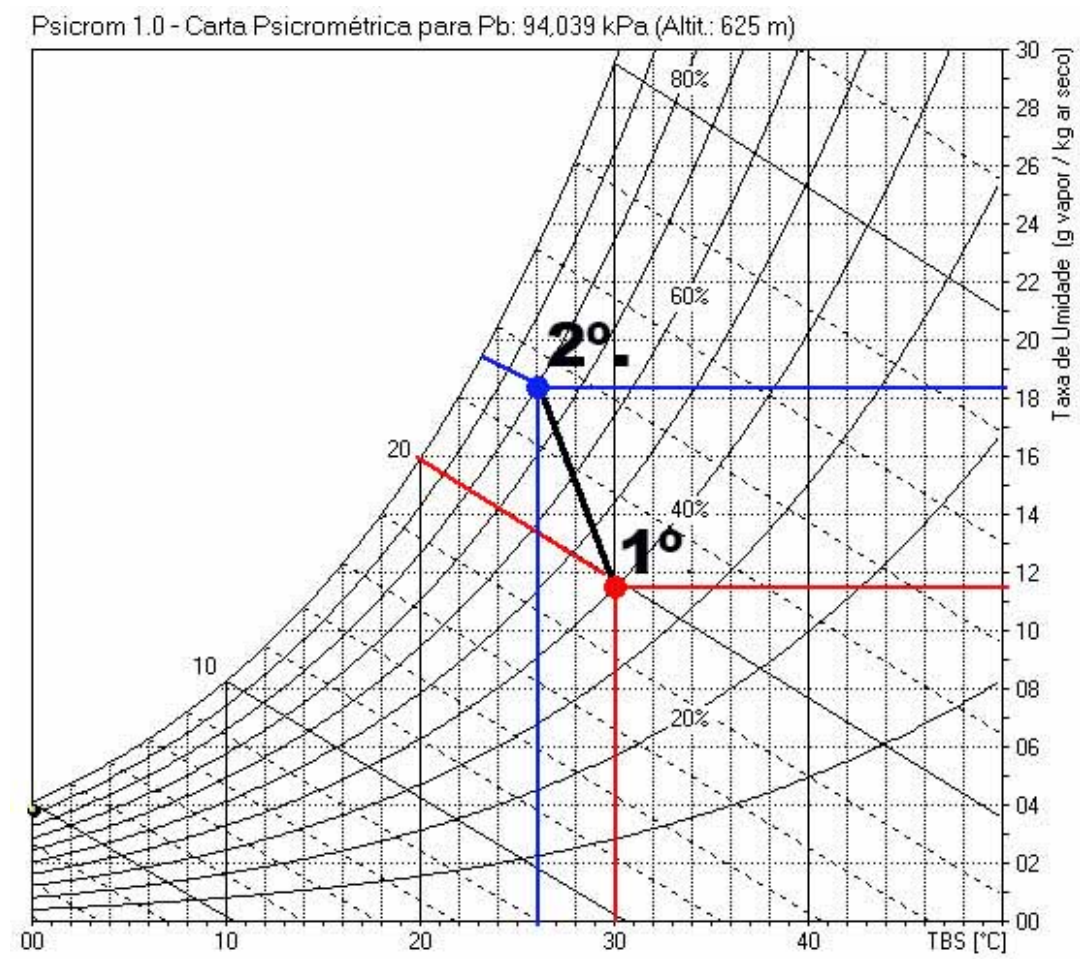

Fonte: adaptada de Torreira (1976), ASHRAE (AMERICAN..., 1996) e Roriz (2003). 
Givoni (1994) classifica os sistemas de resfriamento evaporativo de duas maneiras em relação ao processo de evaporação: resfriamento evaporativo direto (RED) e resfriamento evaporativo indireto (REI). O primeiro ocorre quando o ar, umidificado e resfriado, é introduzido no interior da edificação por meios mecânicos ou passivos, e tanto a taxa de umidade relativa quanto a de umidade absoluta do ar aumentam. Maurya, Shrivastav e Shrivastava (2014) e Givoni (1998) relatam que esse processo pode ser aplicado em regiões de clima quente e seco, pois o contato direto do usuário com o ar umedecido pode melhorar as condições de conforto térmico. Em climas quentes e úmidos, o efeito de resfriamento é menor devido ao alto teor de umidade presente no ar circundante; no entanto, a taxa de evaporação pode aumentar à medida que o movimento do ar aumenta.

Já o REI ocorre quando a envoltória do edifício, paredes e/ou cobertura, está em contato com a água e, ao ganhar calor pela radiação, é resfriada pela evaporação da água em contato. Como consequência, a temperatura do ambiente interno diminui sem interferir diretamente na umidade do ar interno. Gonzalez e Krüger (2013) mostram que a técnica de REI pode obter bons resultados em locais com clima quente e úmido também, pois a umidade relativa do ar não será alterada no ambiente interno. Dessa maneira, não há possibilidade de o ar interno saturar e provocar sensação de desconforto com o ambiente abafado. Há também os sistemas mistos, que combinam as duas estratégias, conforme relatam Santamouris e Kolokotsa (2013).

Segundo a American Society of Heating Refrigerating and Air Conditioning Engineers (AMERICAN..., 1995), o REI se dá pela evaporação da água que ocorre com troca de calor sensível através de um trocador de calor. Em ambos os casos - RED e REI - ou na combinação das duas técnicas, o resfriamento do ar depende das condições psicrométricas do ar externo. Normalmente, os processos de resfriamento evaporativo envolvem somente calor sensível.

Nos últimos anos têm sido amplamente aplicados no mercado brasileiro equipamentos que utilizam o sistema de RED como alternativa aos equipamentos mecânicos de condicionamento de ar por compressão. O processo usado por tais equipamentos consiste na redução da temperatura do ar pela evaporação da água no interior do ambiente e propõe diminuir o consumo de energia elétrica e melhorar a qualidade do ar interno. O sistema é composto de um painel de material inerte e poroso chamado popularmente de pad cooling, no qual o ar, ao atravessá-lo, é umedecido e lançado para o interior do edifício. De acordo com Chaudhari et al. (2015), o painel pode ser de tecido, de argila expandida, de material fibroso ou de qualquer outro material orgânico ou inorgânico que não contamine o ar ou a água. $\mathrm{O}$ ar externo que passa pelo painel resfriador é sugado por um ventilador e enviado para o interior do ambiente. Em geral, o sistema pode ser alimentado com água da rede pública ou de um reservatório. Neste caso, a água, com o auxílio de uma bomba elétrica, circula do reservatório para a parte superior do painel, e o excesso de água não evaporada é coletado e reaproveitado no processo (Figura 2).

Entre os principais fatores que motivam a aplicação das técnicas de resfriamento evaporativo, segundo Gonzalez e Krüger (2013), Chaudhari et al. (2015) e Krüger et al. (2016), estão as questões relacionadas à saúde dos usuários dos edifícios, a possível redução do consumo de energia elétrica para a adequação térmica dos ambientes, a versatilidade e adaptabilidade devido à facilidade de operação, a baixa exigência por manutenção e a necessidade de alternativas tecnológicas condizentes com o clima de cada região.

\section{Figura 2 - Princípio de funcionamento do RED}

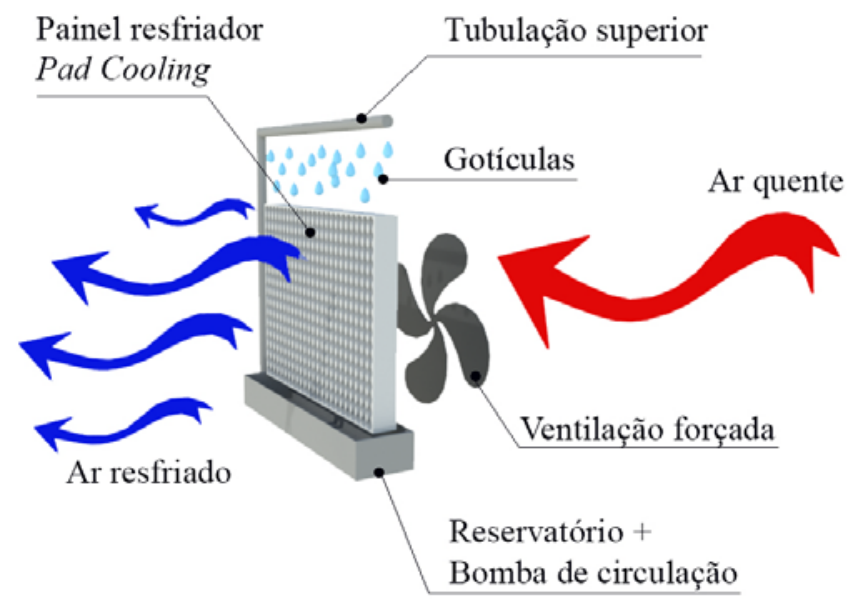

Fonte: adaptada de Maurya, Shrivastav e Shrivastava (2014). 
Segundo Deschenes (2014) e Yao-Dong et al. (2013), o ser humano vem sofrendo cada vez mais influências decorrentes da exposição ao calor tanto em ambientes internos quanto externos. Experiências bem-sucedidas na arquitetura vernacular, de acordo com Ozturk (2003), fizeram com que técnicas de resfriamento evaporativo fossem desenvolvidas em ambientes de permanência humana em diversas partes do mundo, de variados tipos climáticos.

Devido ao fato de sistemas condicionadores de ar por compressão exigirem ambientes hermeticamente fechados para que tenham bom funcionamento, a renovação constante do volume de ar interno das edificações fica prejudicada. O aumento das concentrações de contaminantes químicos e de substâncias particuladas no ar pode reduzir sua qualidade, de forma que Schirmer et al. (2011) admitem que a ventilação dos edifícios é um dos principais fatores que interferem na qualidade do ar interno, a qual está associada a doenças como rinite alérgica, bronquite, asma e síndrome dos edifícios doentes (SED). Estima-se que ocorra cerca de 1,6 milhão de mortes por ano em decorrência da exposição de usuários à alta concentração de partículas e gases encontrados em ambientes fechados, o que pode ser responsável por quase de 3\% das mortes mundiais (WORLD..., 2015). No Brasil, em 2011, as doenças respiratórias crônicas foram a terceira causa de morte no conjunto de doenças crônicas não transmissíveis segundo a Secretaria de Vigilância em Saúde (SECRETARIA..., 2016), uma das maiores ameaças à saúde pública.

Os elevados custos para a instalação e a manutenção de filtros e dutos dos equipamentos condicionadores de ar convencionais, a preocupação em garantir maior eficiência energética às edificações, o aumento geral das tarifas de energia no Brasil, o aumento paulatino da geração de energia primária por fontes não renováveis são fatores que corroboram ainda mais a necessidade de estudos que comprovem a eficiência de sistemas alternativos de condicionamento térmico ambiental (CHAUDHARI et al., 2015; KRÜGER et al., 2016). O Programa Nacional de Conservação de Energia Elétrica (PROGRAMA..., 2008) destaca que o consumo de energia elétrica por uso final no Brasil em edificações públicas e comerciais pode chegar a 40\% do consumo total de energia e que os sistemas de ar condicionado respondem pela maior fatia nesse setor. Portanto, ações voltadas à eficiência energética são altamente relevantes como políticas de economia e preservação do meio ambiente. Khandelwal, Talukdar e Jain (2011) revela que um sistema de RED pode oferecer uma economia entre 12,05\% e 15,79\% de energia para condicionamento térmico de uma edificação no consumo anual, mantendo o predicting mean vote (PMV) entre -1 e +1 na maioria das horas do ano.

Dessa forma, os elevados gastos da saúde pública, principalmente com os problemas respiratórios na estação seca do ano, somados ao excessivo consumo energético dos sistemas convencionais de condicionamento de ar, obrigam o desenvolvimento de tecnologias auxiliares que melhorem a qualidade ambiental dos espaços internos de trabalho e convivência. Nesse sentido, os painéis dos aparelhos de RED apresentam vantagens em relação ao condicionamento de ar convencional, pois o pad cooling pode funcionar como filtro para as impurezas contidas no ar externo e contribui para eliminar muitos contaminantes, como poeira, fungos e bactérias, os quais são lavados na água recirculada. Conforme a água evapora, o ar ventilado e resfriado é fornecido ao ambiente (MAURYA; SHRIVASTAV; SHRIVASTAVA, 2014).

O objetivo deste estudo foi identificar o comportamento dinâmico da temperatura e da umidade do ar interno e o consumo de água em uma célula-teste com o uso de um equipamento eletromecânico de resfriamento evaporativo direto (RED) em duas condições atmosféricas distintas, uma quente e úmida e outra quente e seca.

\section{Materiais e método}

A proposta de avaliação do sistema de RED se baseou na observação comparativa da variação das TBS e de TBU e do consumo de água no interior de duas células-teste. A relação entre as temperaturas indicou a variação da umidade relativa (UR) com o uso do ábaco psicrométrico nos ambientes internos. Ambas as células comparadas são semelhantes em termos construtivos, e o comportamento térmico delas foi observado simultaneamente sob as mesmas condições atmosféricas.

\section{Local do experimento}

As análises foram feitas no canteiro experimental do Centro de Recursos Hídricos e Estudos Ambientais (CRHEA) da Universidade de São Paulo (USP), localizado no município de Itirapina, $15 \mathrm{~km}$ ao sul do centro da cidade de São Carlos, com 22 ${ }^{\circ} 11^{\prime} 15^{\prime}$ ” de latitude e 4756'15” de longitude.

O canteiro experimental conta com 15 células edificadas (Figura 3), entre as quais três foram usadas para monitoramento, sendo uma com a aplicação do sistema RED, outra como uma célula de controle, sem qualquer 
sistema ativo de resfriamento, chamada de célula testemunho, e uma terceira para abrigar os equipamentos de monitoramento.

\section{Descrição das Células-Teste}

As células-teste são construídas com tijolos cerâmicos maciços, paredes com 0,12 m de espessura, pintura branca de cal interna e externa, e cobertura com telhas de fibrocimento fixadas na estrutura de madeira e laje com lajotas cerâmicas com capeamento de concreto, totalizando $7 \mathrm{~cm}$ de espessura. Cada célula tem $16 \mathrm{~m}^{3}$ de volume de ar interno. A distância entre as células possibilitou a distribuição igualitária de radiação solar e de circulação de ar conforme a Figura 4, da implantação completa do canteiro experimental.

Os dados climáticos foram coletados pela Estação Climatológica Automática Campbell Scientific CR21X, instalada no CRHEA da Escola de Engenharia de São Carlos, no município de Itirapina, SP.

A célula 1 é a testemunho, e a 2 foi usada apenas para abrigar o datalogger e distribuir as instalações elétricas e de termopares.

Na célula-teste 3 foi instalado um equipamento eletromecânico comercial de RED com o uso de painel resfriador - pad cooling (Figuras 5 a 8), modelo Ecobrisa EB-20, com vazão de ar máxima de aproximadamente de $2.800 \mathrm{~m}^{3} / \mathrm{h}$, recomendado para ambientes com volume de até $30 \mathrm{~m}^{3}$. De acordo com o fabricante, o equipamento utilizado no experimento (ECOBRISA, 2019), em geral, tem a capacidade máxima de reduzir a TBS interna do ar na ordem de $11^{\circ} \mathrm{C}$ em relação à TBS externa.

Figura 3 - Canteiro experimental
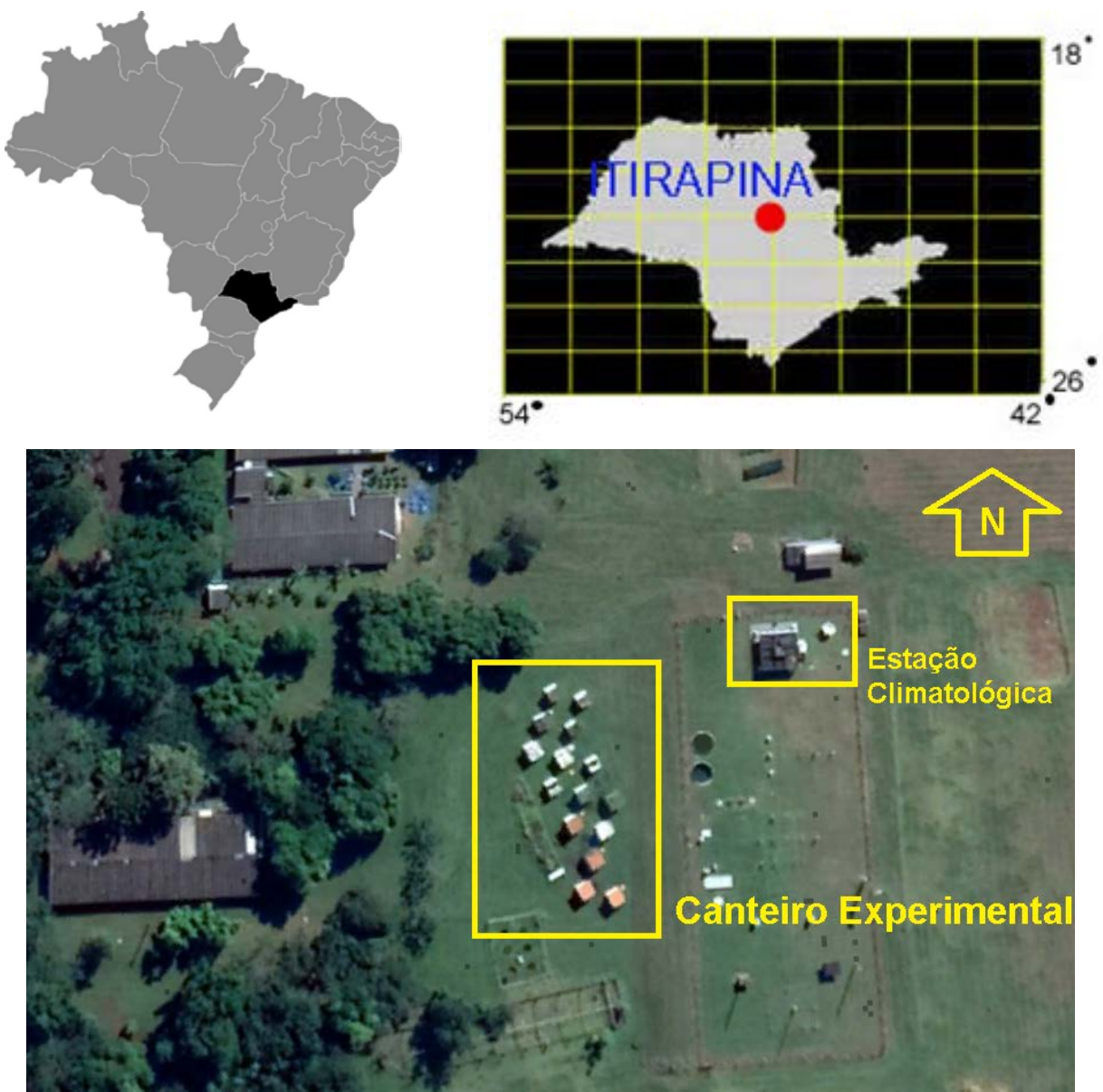

Fonte: adaptada de CRHEA (2019) e Google Earth (2018). 
Figura 4 - Canteiro experimental

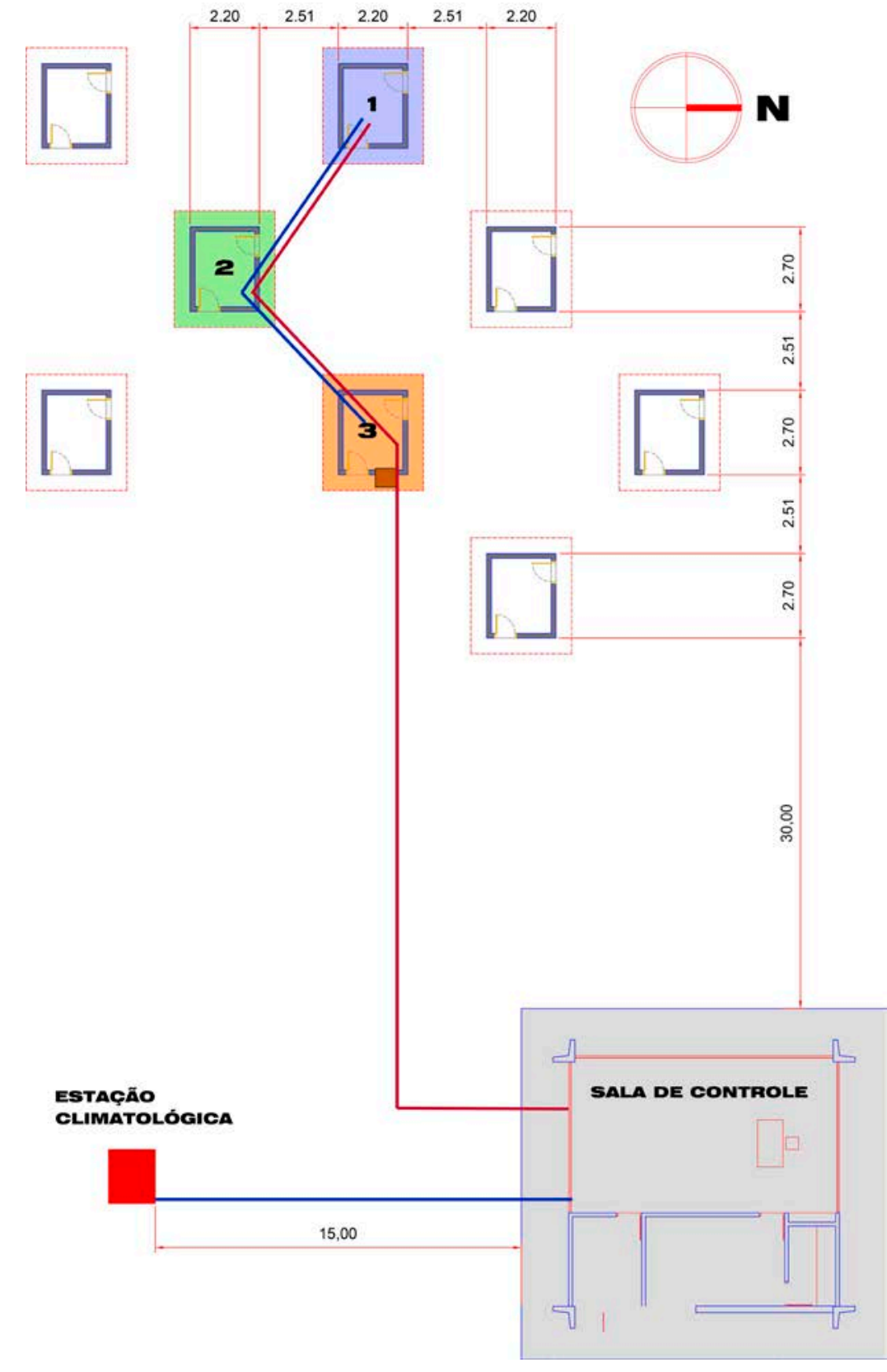

Nota: Legenda:
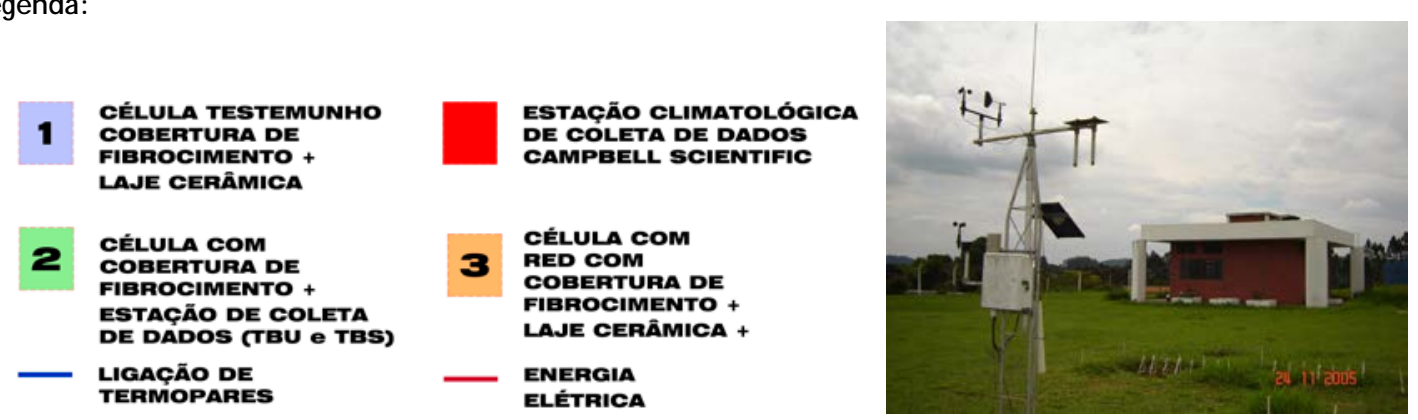

Tal sistema é formado por dois ventiladores com motores elétricos de $50 \mathrm{~W}$ de potência cada um, dois painéis resfriadores do tipo colmeia de celulose resinada de 30×45x20 cm, um reservatório inferior de água com capacidade de 1,50 l, uma bomba de circulação da água e um painel de controle com cinco velocidades de 
funcionamento. A água é bombeada para a parte superior do aparelho por uma tubulação e escorre pelo painel de celulose, que possui grande área superficial exposta à passagem do ar, promovida pelos ventiladores localizados na parte posterior do equipamento. Parte da água evapora nesse percurso e retira calor do ar ambiente; assim, a temperatura é reduzida e a umidade do ar se eleva. O aparelho não conta com um termostato que regule o funcionamento dos motores por meio dos índices de temperatura interna, e, dessa maneira, o consumo energético não depende das condições de temperatura do ar, e, sim, do controle de velocidade dos motores do usuário.

O equipamento de RED na célula-teste foi posicionado a 1,50 m do piso com uma abertura na parede oposta para a exaustão natural e a renovação constante do ar ambiente na proporção de 1/12 da área do piso interno, conforme recomendação do fabricante do equipamento. Tanto a entrada quanto a saída de ar da célula-teste foram protegidas da radiação solar direta com dispositivos adicionais de sombreamento, constituídos de EPS na cor branca. Os termopares, três TBS e três TBU, foram instalados em três alturas diferentes $-0,70 \mathrm{~m}, 1,40$ m e 2,10 m - em ambas as células, conforme indicado pela Figura 9, para que o gradiente vertical da temperatura interna fosse avaliado e comparado com os valores coletados na célula testemunho.

\section{Figura 5 - Vista frontal do aparelho RED}

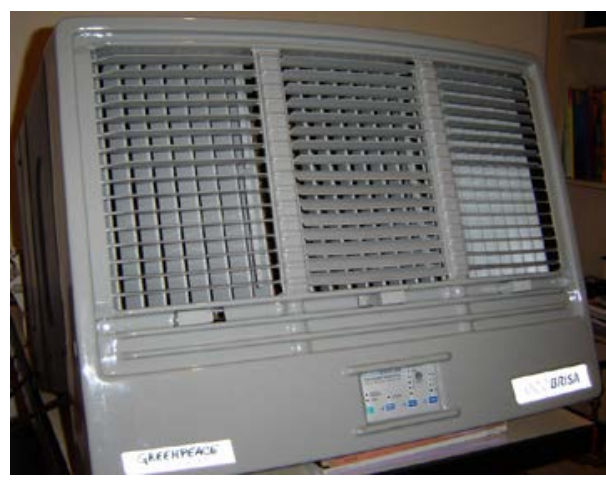

Figura 6 - Vista interna pad cooling

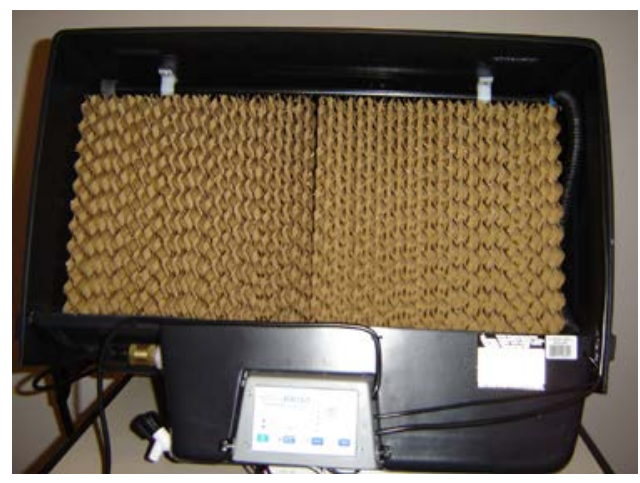

Figura 7 - Vista do motor

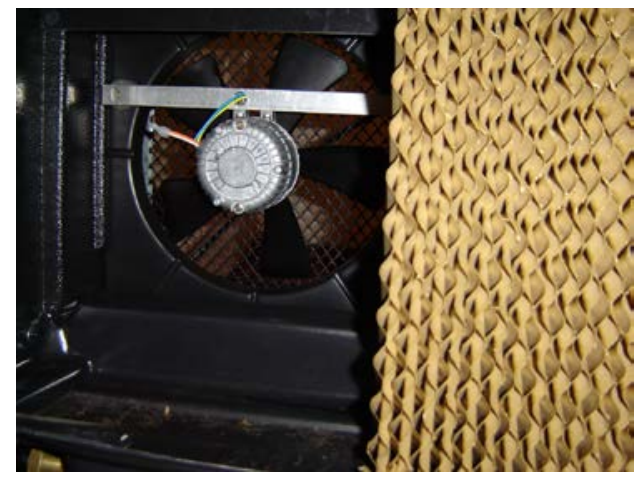


Figura 8 - Painel de controle de velocidades

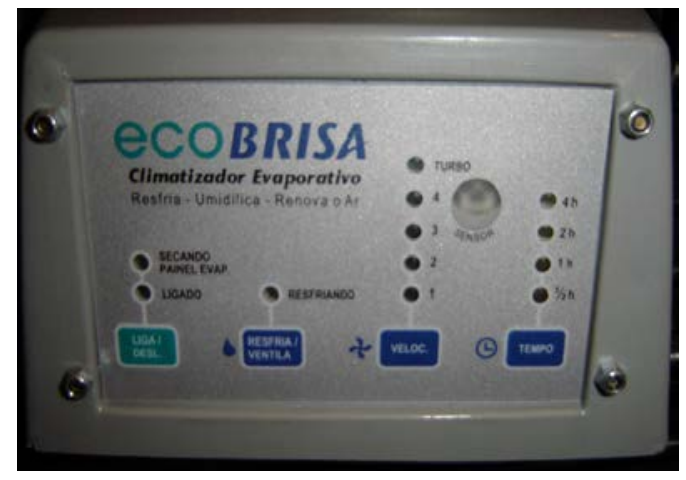

Figura 9 - Esquema de instalação do resfriador evaporativo com os termopares

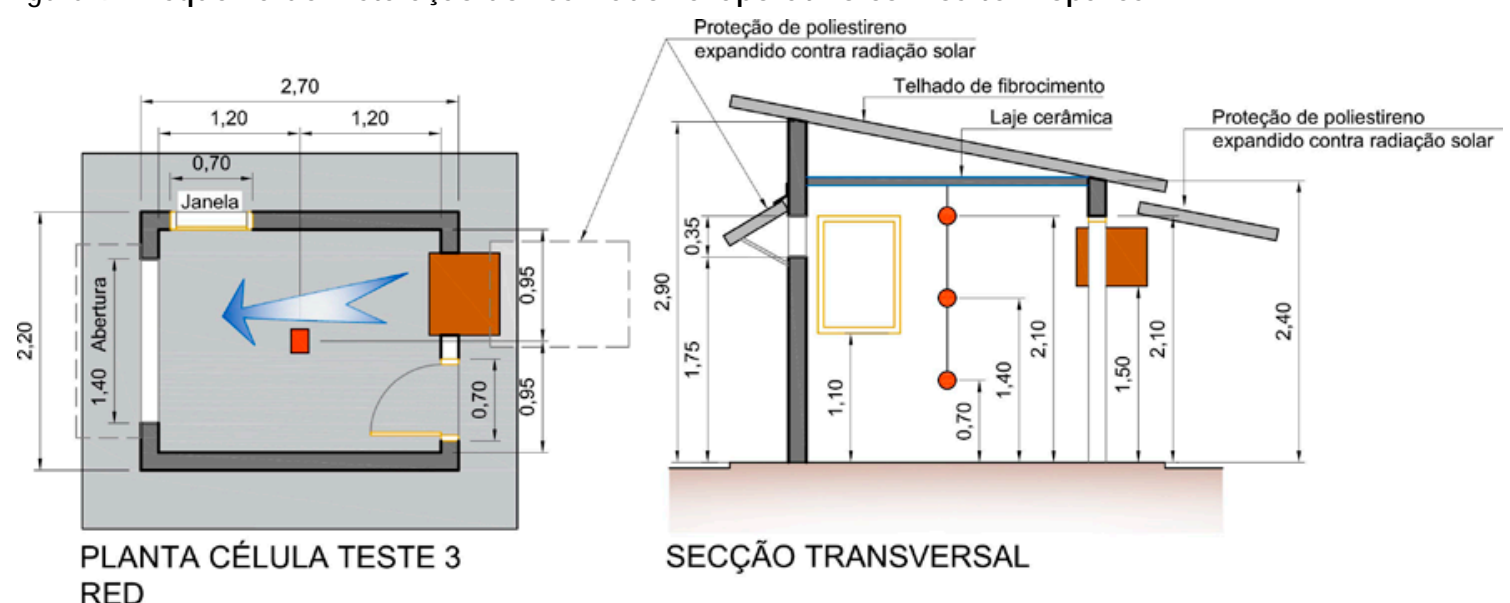

Nota: Legenda:

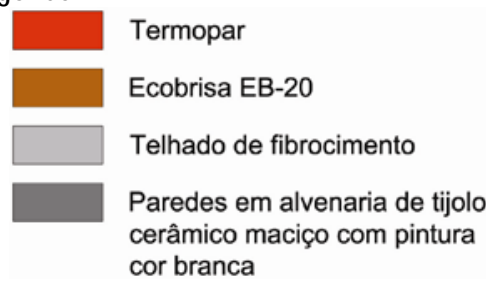

São mostradas nas Figuras 10 e 11 respectivamente a face leste (entrada de ar) e a face oeste (saída de ar) da célula-teste com RED com os protetores contra radiação solar. A Figura 12 apresenta a célula testemunho, que conta com um conjunto de termopares internamente posicionados nas alturas 0,70 m, 1,40 m e 2,10 m e entrada e saída de ar com tamanhos semelhantes à célula 3 para ventilação natural.

A velocidade do ar interna foi medida com um termoanemômetro Digital Instrutherm TAVR - 650 posicionado a 1,40 m de altura, junto ao sensor de TBS e TBU, no centro da célula-teste com RED, e a velocidade de funcionamento do equipamento permaneceu no máximo durante os dois períodos de análise.

\section{Sistema de aquisição de dados}

Os valores de TBS de TBU do ar interior de cada célula-teste são coletados com termopares do tipo T (cobreconstantan). Consistem em um conjunto formado por dois fios condutores de eletricidade, no caso um fio de cobre e outro composto de uma liga de cobre e níquel chamada de "constantan”. Os fios são soldados entre si em um ambiente com gás argônio apenas na extremidade destinada à medição da temperatura no interior da célula-teste. Essa extremidade fica protegida da possível influência da radiação emitida pelos materiais ao redor por um tubo de PVC branco chamado de shield ou abrigo meteorológico, nas dimensões de $25 \mathrm{~cm}$ de comprimento e 7,5 cm de diâmetro. A extremidade oposta do cabo é conectada à estação de coleta de dados CR 10X Campbell Scientific, na qual os dados são transferidos e armazenados. O sistema de coleta de 
temperaturas Campbell Scientific (2019a), também conhecido como psicrômetro, é mostrado esquematicamente na Figura 13, e na Figura 14, o conjunto em funcionamento no interior de uma célula-teste.

O abrigo meteorológico contribui para evitar que o efeito da radiação interfira nas medições de TBS e TBU, e o pequeno ventilador instalado na parte posterior do conjunto cria uma corrente de ar no interior do abrigo para facilitar a evaporação da água presente na gaze úmida do termopar de TBU. O reservatório de água está disposto na parte inferior do dispositivo e garante que o termopar destinado à medição de TBU fique sempre úmido por meio de uma ligação de gaze entre o reservatório e a extremidade dos fios. A precisão do sistema de aquisição de dados foi aferida em uma campanha que comparou medições de TBS do ar externo coletados simultaneamente pela Estação Climatológica do CRHEA e pelos sensores usados no experimento durante três dias quentes e secos consecutivos. Os dados registrados pelos sensores apresentaram imprecisões de no máximo $0,5^{\circ} \mathrm{C}$ em relação aos dos sensores da estação, o que é similar ao desempenho de muitos sensores industrializados disponíveis no mercado atualmente.

Figura 10 - Face leste da célula RED

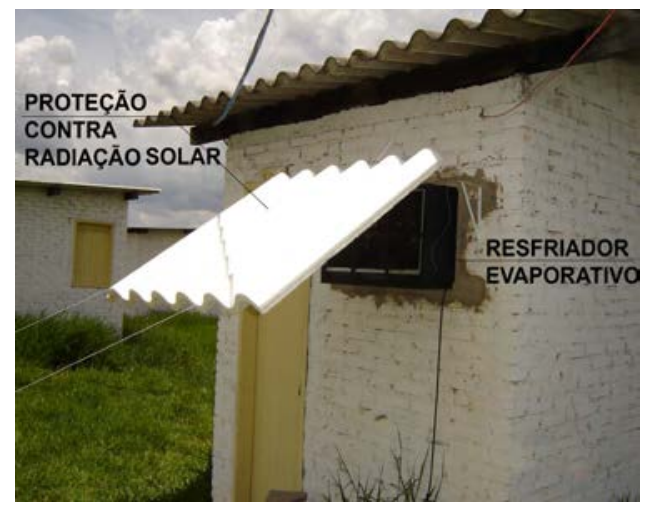

Figura 11 - Face oeste da célula RED

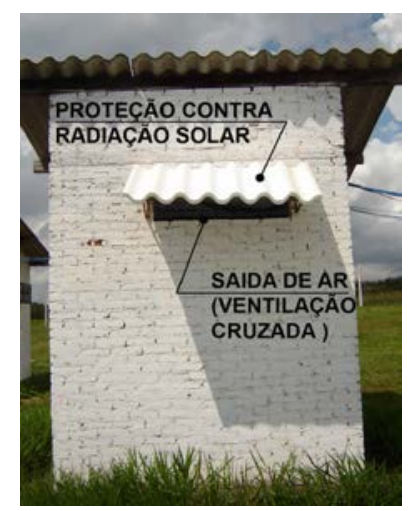

Figura 12 - Célula testemunho

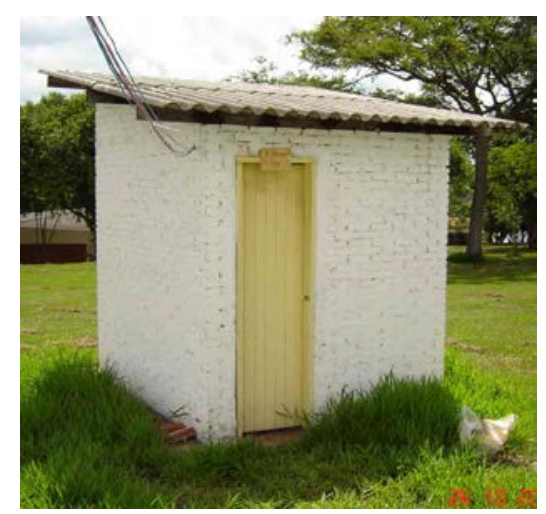


Figura 13 - Esquema do psicrômetro

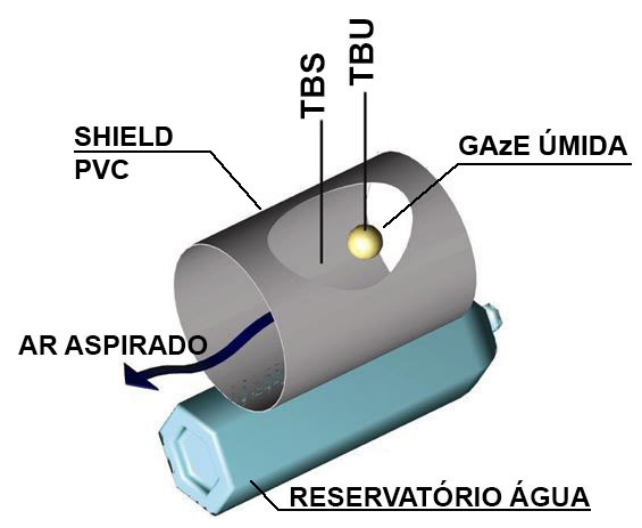

Figura 14 - Montagem do psicrômetro

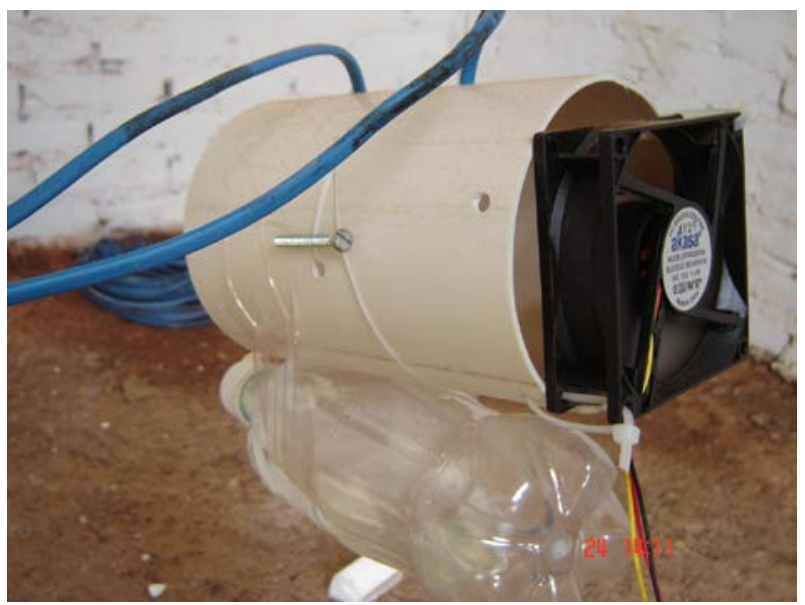

No caso específico da célula com RED, foram instalados dois termopares adicionais, um próximo do painel resfriador de celulose e outro na saída de ar do lado oposto, ambos na altura de 1,80 m do piso, para se avaliar o gradiente horizontal de temperatura interna (Figuras 15 e 16).

A aquisição de dados no interior de cada célula-teste foi feita automaticamente por meio de um datalogger CR 10X Campbell Scientific (2019a), instalado dentro de uma caixa ambientalmente selada, disposta na célula 2. Os sensores vindos do interior das células-teste são conectados ao datalogger, que armazena e disponibiliza os dados.

A alimentação de energia do sistema de aquisição de dados foi garantida de forma segura com o uso de um painel solar fotovoltaico capaz de carregar uma bateria de $12 \mathrm{~V}$, na qual o datalogger foi conectado. Dessa maneira, foi minimizado o risco de qualquer pane no sistema elétrico comprometer a coleta de dados, pois a bateria mantém o sistema em funcionamento.

Um aparelho multiplexador Campbell Scientific (2019c) AM416 foi usado para ampliar a capacidade de ligação de pontos de medição do datalogger CR10X, de tal forma que foi possível registrar dados em oito pontos diferentes de coleta no experimento. Os componentes da ligação são apresentados nas Figuras 17 a 20.

O software usado para a aquisição de dados do datalogger foi o PC208W 3.3, que é compatível com sistema operacional Microsoft Windows e foi desenvolvido pela Campbell Scientific Inc. Os dados registrados nas células-teste e armazenados no CR10X foram transferidos para um microcomputador pessoal e trabalhados no software Microsoft Excel, que auxiliou na produção das tabelas e dos gráficos necessários para o estudo.

\section{Aplicação do Ábaco Psicrométrico}

O ábaco psicrométrico foi usado para a obtenção dos dados referentes à umidade relativa do ar no interior de cada célula-teste, já que o sistema de ligação só fornece os dados de TBU e TBS. Os valores de TBU e TBS 
adquiridos no canteiro experimental foram inseridos no software Psicrom 1.0, desenvolvido por Roriz (2003), sendo assim calculados automaticamente. O software Psicrom 1.0 disponibiliza uma tabela com as relações psicrométricas obtidas automaticamente mediante a inserção dos dados de TBU e TBS, possibilitando a análise das taxas de umidade, a umidade absoluta e a umidade relativa do ar nos momentos desejados, com os dados coletados no canteiro experimental.

Figura 15 - Termopar na superfície do pad cooling

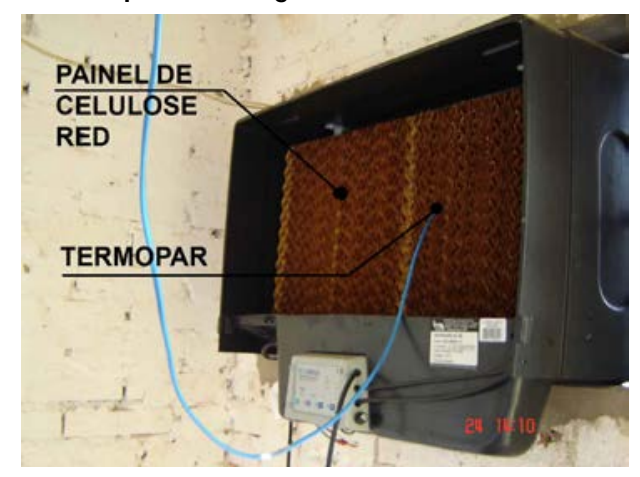

Figura 16 - Termopar na saída de ar da célula-teste com RED

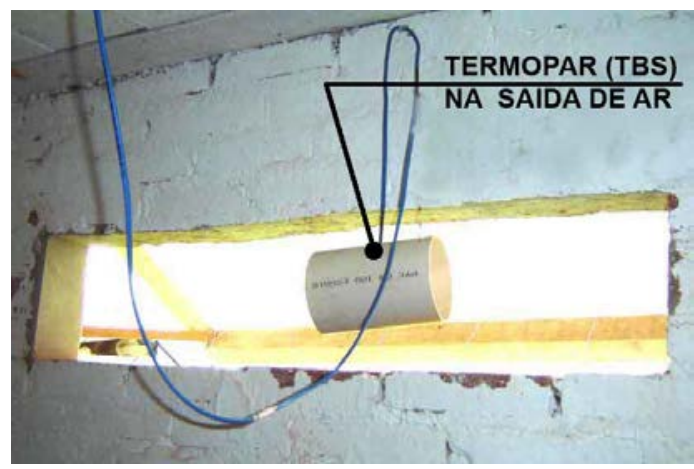

Figura 17 - Datalogger CR 10X

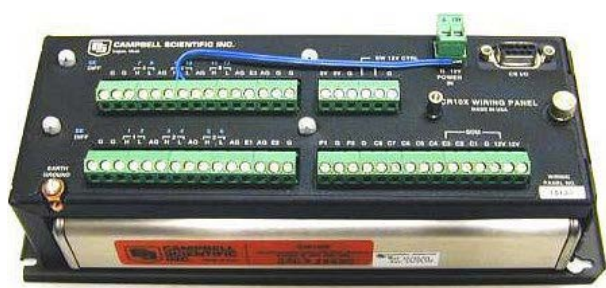

Fonte: adaptada de Campbell Scientific (2019a).

Figura 18 - Multiplexador AM416

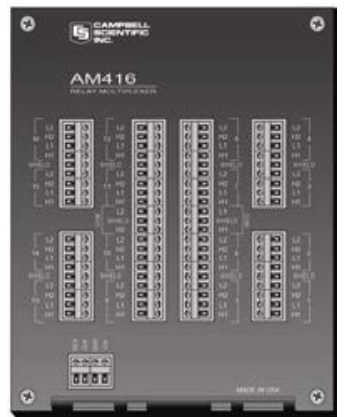

Fonte: adaptada de Campbell Scientific (2019c). 
Figura 19 - Painel solar fotovoltaico

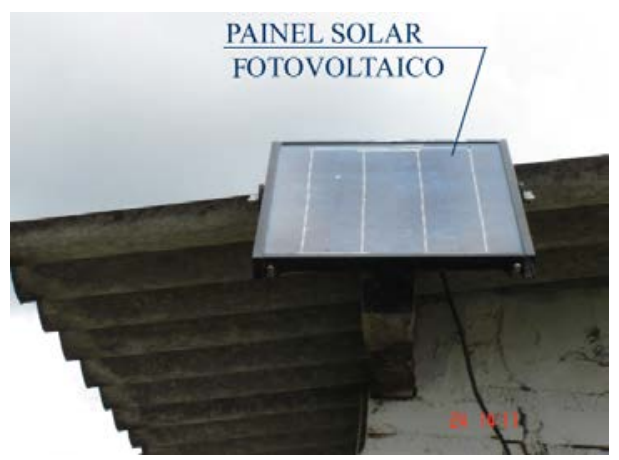

Fonte: adaptada de Campbell Scientific (2019a).

Figura 20 - Esquema de ligações de termopares e datalogger nas células

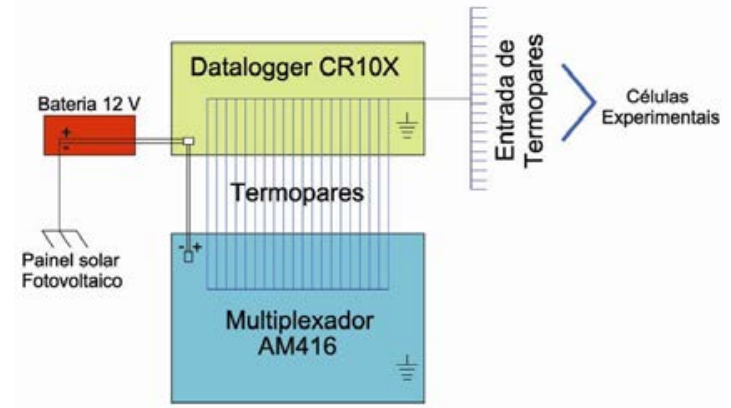

Fonte: adaptada de Campbell Scientific (2019a).

\section{Medição do consumo de água}

O consumo de água foi medido a cada hora na célula 3 durante o período de análise com o funcionamento do aparelho RED em velocidade alta. Após os dois períodos de análise, a velocidade de funcionamento do aparelho foi reduzida ao mínimo, de forma a indicar a mínima capacidade de resfriamento do aparelho. Uma garrafa plástica graduada de $10 \mathrm{l}$ (Figura 21) foi usada para as leituras de consumo, minimizando a possibilidade de perdas de água pelas conexões.

A variação de consumo de água foi avaliada considerando diferentes faixas de umidade relativa do ar, de temperatura externa e da velocidade alta e baixa de funcionamento dos motores do RED, as quais possibilitam velocidades do ar interno da ordem de $0,1 \mathrm{~m} / \mathrm{s}$ e $0,8 \mathrm{~m} / \mathrm{s}$ respectivamente, medidas a $1,40 \mathrm{~m}$ de altura no centro da célula-teste.

\section{Períodos de análise}

O parâmetro climático mais importante na previsão das temperaturas máximas de um ambiente interno é a média diária da temperatura ao ar livre, segundo Givoni (1999), de acordo com diferentes condições de sombreamento, ventilação e cor do envelope. Os fatores climáticos, sobretudo as características das massas de ar atuantes em um território, são determinantes na eficiência dos sistemas de resfriamento evaporativo, por isso é importante que estudos experimentais em células-teste considerem conceitos de climatologia dinâmica, conforme relatam Cardoso, Claro Neto e Vecchia (2012) e Cardoso e Vecchia (2013). Assim, a abordagem da climatologia dinâmica contribui para analisar informações em dias típicos e procura descrever os efeitos termodinâmicos mais significativos no ambiente construído. 
Figura 21 - Instalação de garrafa plástica para medição de consumo de água do resfriador evaporativo

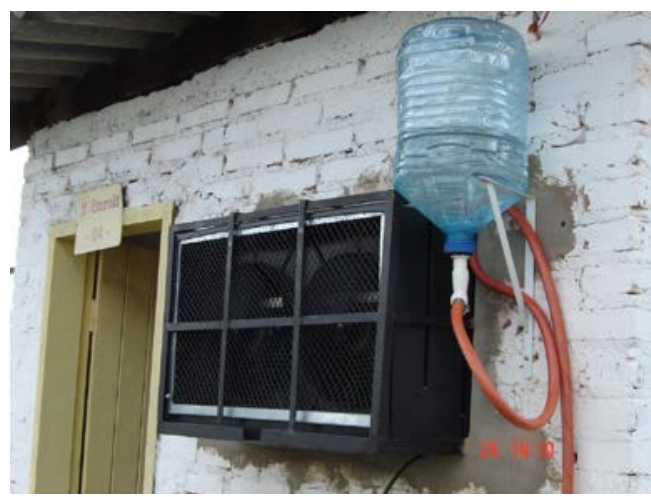

Nesse sentido, torna-se relevante considerar a circulação atmosférica típica do interior paulista, que, segundo Nimer (1979), se encontra no limite de duas zonas climáticas - a intertropical e a subtropical. Na primeira se desenvolvem climas controlados por massas equatoriais e tropicais, enquanto na segunda se desenvolvem climas controlados por massas tropicais e polares. A região Sudeste recebe influências das perturbações das correntes tropicais marítimas do leste-nordeste (E-NE), das correntes polares do sul e das correntes oestenoroeste (W-NW) do interior do continente, pois está situada no cruzamento da circulação desses sistemas, e, embora essa região apresente caráter de transição entre os climas tropicais e temperados, o caráter tropical é o mais marcante, sendo que a região de estudo apresenta clima mesotérmico brando úmido, com três meses secos, entre junho e agosto, e uma estação chuvosa com verão quente e úmido, de outubro a março.

Os períodos alternadamente secos e úmidos podem ser notados principalmente no início da primavera, quando as chuvas passam a ser mais intensas e frequentes, marcando o período de transição entre a estação seca e a chuvosa (CENTRO..., 2019). Essa característica climática possibilitou que as análises fossem realizadas sob condições atmosféricas quente e seca e quente e úmida em dois períodos distintos no mês de novembro, tendo sido a fase pré-frontal da atuação dos sistemas atmosféricos que atuaram na região a escolhida como referência para a determinação dos períodos de observação do funcionamento do sistema de resfriamento evaporativo. É durante essa fase que as temperaturas se elevam e que a umidade do ar e a pressão atmosférica diminuem e podem afetar as condições de conforto e saúde humana, segundo Vecchia (1997). Portanto, são os períodos do tempo meteorológicos que podem representar significativamente o comportamento do ambiente construído das células-teste.

Com o método experimental elaborado para a avaliação da técnica RED, foi possível analisar em tempo real as influências dos fatores climáticos, dos componentes construtivos do espaço estudado e dos processos físicos que envolvem as reações de resfriamento do ar diretamente no interior da célula-teste em questão. Foram recortados dois períodos para a avaliação do funcionamento de RED, nos quais ocorreram situações climáticas típicas da região.

$1^{\circ}$ Período de análise - 5, 6 e 7 de novembro - quente e úmido.

$2^{\circ}$ Período de análise - 15, 16 e 17 de novembro - quente e seco.

O $1^{\circ}$ período de análise foi escolhido para demonstrar como as condições meteorológicas podem prejudicar o funcionamento do sistema de RED, principalmente por ter apresentado elevados índices de umidade atmosférica, o que interfere nas taxas de evaporação e minimiza as possibilidades de redução da temperatura do ar interno.

O $2^{\circ}$ período de análise apresentou índices de umidade baixos e temperaturas elevadas, o que favoreceu o funcionamento e a eficiência do sistema de RED. Assim, foi possível registrar os resultados em um período cujas condições atmosféricas favoreceram a redução das temperaturas internas do ar da célula-teste devido ao aumento das taxas de evaporação.

\section{Análise de resultados e discussão}

Em geral, o sistema de RED é afetado pela variação da TBS e da TBU do ar, segundo Maurya, Shrivastav e Shrivastava (2014), as quais dependem diretamente das características das massas de ar atuantes em uma 
região e influenciam a variação de umidade absoluta e relativa do ar interno. Ou seja, o efeito de resfriamento evaporativo depende da taxa de evaporação da água no ar, conforme relatam Watt e Brown (1997).

\section{Primeiro período}

Durante o primeiro período de análise de resultados - entre os dias 5 e 7 de novembro - o ar de alta pressão marítima em superfície trouxe muita umidade do mar, a qual invadiu as faixas leste, litorânea e nordeste de São Paulo, tendo provocado grande instabilidade atmosférica (CENTRO..., 2005). Durante esse episódio climático, as temperaturas mais altas registradas ultrapassaram $30{ }^{\circ} \mathrm{C}$, e a umidade relativa média foi de 97,26\%, decorrente da atuação da Massa Tropical Atlântica (mTa).

A Figura 22 compara a variação das TBS nas células com RED - TBS ${ }^{\circ} \mathrm{C}$ RED 1,40 m - e testemunho - TBS Test ${ }^{\circ} \mathrm{C} 1,40 \mathrm{~m}$-, assim como a temperatura e a umidade relativa do ar externo - TEMP Ext ${ }^{\circ} \mathrm{C}$ e UR Ext \% registradas pela Estação Climatológica do CRHEA-USP (CENTRO..., 2005).

Verifica-se que os valores de TBS registrados na célula-teste com RED permaneceram acima daqueles registrados na célula testemunho, chegando a $3,0{ }^{\circ} \mathrm{C}$. Durante o $1^{\circ}$ período os efeitos do resfriamento evaporativo não puderam ser notados devido à dificuldade de evaporação da água no ambiente interno, notadamente quente e úmido.

O gradiente vertical de TBS na célula com RED apresentou variação máxima de $1,74{ }^{\circ} \mathrm{C}$ durante os três dias consecutivos do $1^{\circ}$ período de análise, conforme a Figura 23. A baixa amplitude térmica ocorreu devido à concentração de água no ar do ambiente interno, propiciada tanto pelas características da massa de ar atuante, quanto pelo próprio aparelho de RED, que não conta com um sensor para cessar automaticamente o fornecimento de umidade. A elevada umidade relativa da massa de ar atuante naqueles dias dificultou a evaporação da água no ambiente interno e, consequentemente, a queda nos índices de temperatura.

Na Figura 24 verifica-se que os valores de temperatura medidos no painel de celulose do resfriador evaporativo - T ${ }^{\circ} \mathrm{C}$ Pad RED - permanecem próximos dos valores medidos na saída de ar do ambiente - T ${ }^{\circ} \mathrm{C}$ Saída ar -, tendo apresentado um gradiente horizontal de $2,11^{\circ} \mathrm{C}$ no dia 6 de novembro.

\section{Segundo período}

Durante o segundo período de análise de resultados - entre os dias 15 e 17 de novembro - a atmosfera se apresentava estável, com céu aberto e pouca nebulosidade. As máximas temperaturas registradas ultrapassaram os $32{ }^{\circ} \mathrm{C}$, os ventos eram predominantes na direção norte, e a umidade relativa mínima do ar chegou a 43,97\%, de acordo com a Estação Climatológica do CRHEA-USP (CENTRO..., 2005). As poucas nuvens sobre a região Sudeste, juntamente com os dados climatológicos, evidenciam a atuação da Massa Tropical Continental (mTc) sobre a região, a qual estava na fase de domínio há aproximadamente 1 semana. Esse episódio climático contribuiu para manter as temperaturas externas elevadas, e a pressão atmosférica e a umidade relativa do ar reduzidas no interior do Estado de São Paulo, principalmente no dia 16 de novembro.

\section{Figura 22 - Comparativo entre os valores de TBS nas duas células-teste em relação aos índices de temperatura e umidade relativa do ar externo no 10 período}
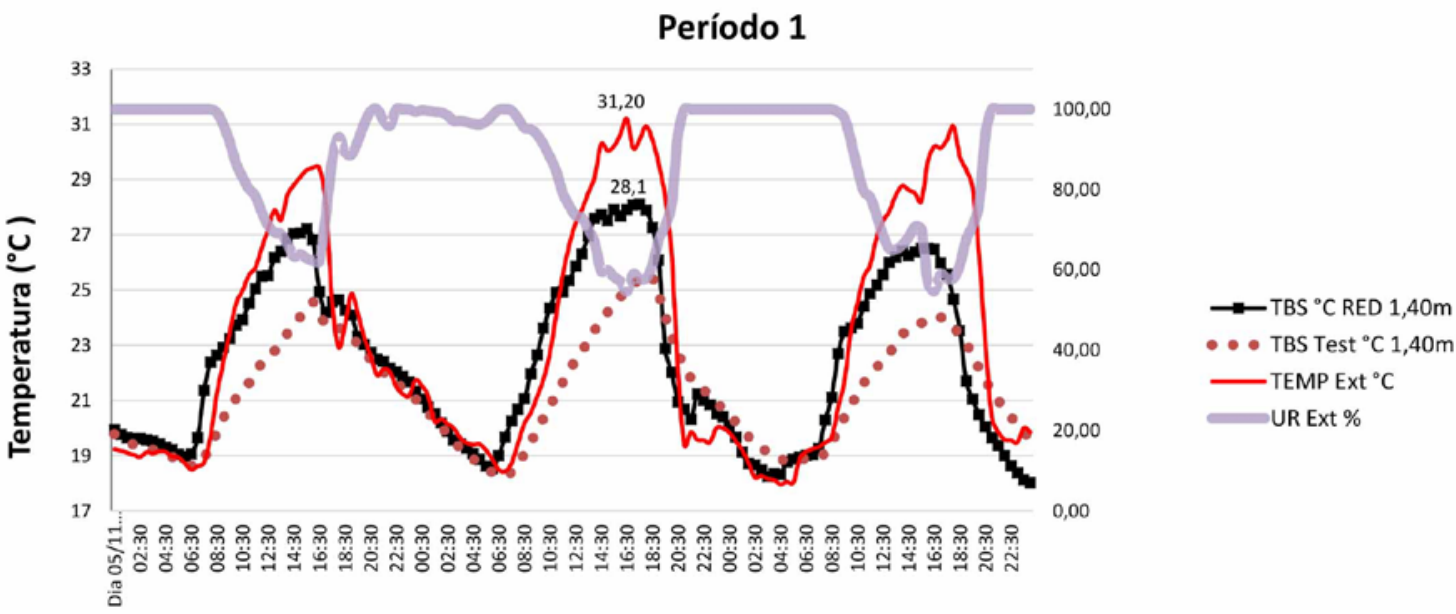
Figura 23 - Gradiente vertical de TBS na célula-teste com RED em três alturas no 1 período

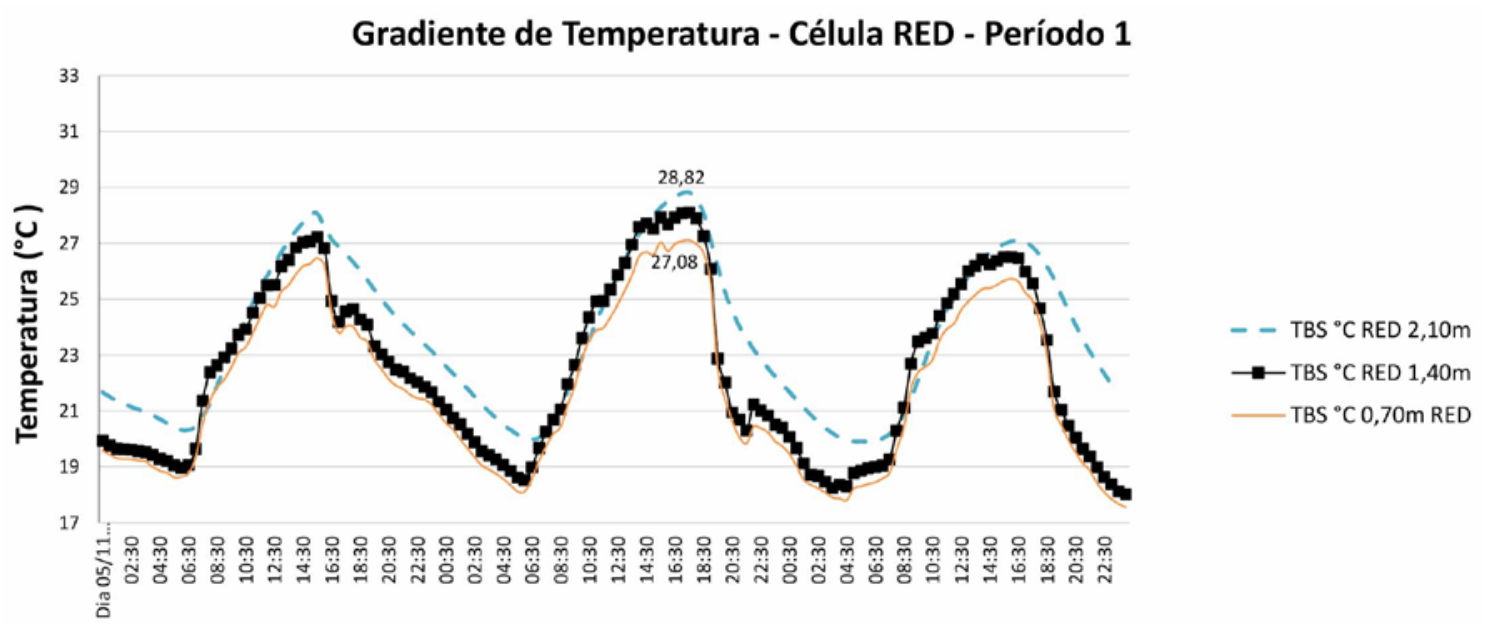

Figura 24 - Gradiente horizontal de TBS na célula-teste com RED em comparação com a temperatura externa do ar no 10 período

Temperatura no Pad e na saida de ar - Período 1

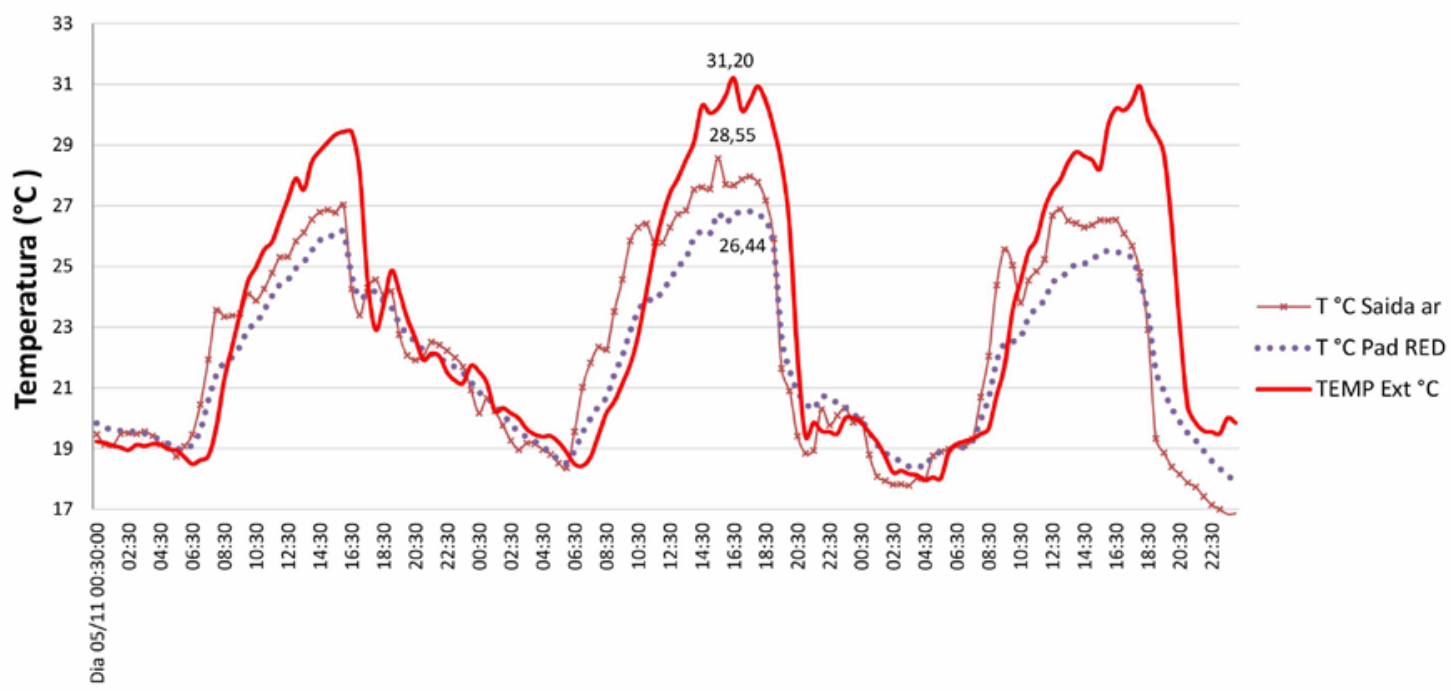

Portanto, nota-se que, ao aumentar a umidade do ar, o gradiente interno de temperatura tende a diminuir.

A Figura 25 apresenta as curvas de TBS do ar interno da célula-teste com RED acompanhando a tendência de oscilação da curva de TBS da célula testemunho e da temperatura externa do ar, mantendo-se aquelas sempre abaixo destas. É importante ressaltar que o período mais quente e mais seco coincide com o momento em que o resfriador evaporativo atinge o ápice de seu desempenho, registrando $6,69{ }^{\circ} \mathrm{C}$ de diferença às $15 \mathrm{~h} 00$ no dia 16 de novembro. Ou seja, a evaporação da água do interior da célula aumenta devido à condição favorável de reduzida umidade relativa do ar externo naquele momento. É exatamente o momento em que a diferença entre a temperatura do interior da célula e a temperatura externa do ar é maior.

A Figura 26 apresenta o gradiente vertical das TBS nas três alturas durante o $2^{\circ}$ período de análise. É possível notar a oscilação das temperaturas nas mesmas frequências, mas com amplitudes menores nos termopares a $1,40 \mathrm{~m}$ e a 0,70 m de altura. Esse fato se deve à maior proximidade do termopar a 2,10 m com a cobertura, a qual pode ter sido influenciada pela incidência da radiação solar e pela transmissão do calor por condução. Assim, foi registrado um gradiente vertical de temperatura de $3,65^{\circ} \mathrm{C}$.

Pela Figura 27, as temperaturas registradas na superfície do painel de celulose do resfriador evaporativo - T ${ }^{\circ} \mathrm{C}$ Pad RED - permaneceram sempre abaixo das temperaturas de saída do ar do ambiente - $\mathrm{T}{ }^{\circ} \mathrm{C}$ Saída ar. Nota-se que nas primeiras horas do período da manhã, quando a umidade relativa costuma ser mais alta, as 
temperaturas tendem a se igualar. $\mathrm{O}$ gradiente horizontal máximo de temperatura registrado foi de $4,3{ }^{\circ} \mathrm{C}$, o que mostra a efetividade do processo de evaporação na redução da temperatura do ar interno durante as horas mais quentes de cada dia. Nesse sentido, o RED se apresenta como alternativa eficiente para reduzir a amplitude térmica diária e aumentar a salubridade de ambientes internos, embora o desenvolvimento de estudos mais apurados seja necessário para garantir a distribuição mais igualitária do ar resfriado no ambiente interno.

Portanto, nota-se que, com a umidade do ar mais baixa, o gradiente interno de temperatura tende a aumentar.

A Figura 28 apresenta a variação da amplitude térmica total nos dois períodos de medição. É possível compreender que durante o período 1 a amplitude térmica da célula testemunho é inferior à da célula com RED. Entretanto, essa tendência se inverte durante o período 2, ou seja, a TBS na célula com RED passa a ser inferior.

É possível constatar que as TBS nas três alturas na Figura 29 estão muito próximas entre si durante o período 1. Em períodos úmidos e nublados a incidência de radiação solar sobre a cobertura é menor. No entanto, devido à elevada umidade relativa do ar, a taxa de evaporação interna às células se reduz, o que provoca a baixa eficiência para resfriamento durante o período 1.

A Figura 30 apresenta que a TBS captada sobre na superfície do pad cooling é inferior às demais, o que atesta que a taxa de evaporação se eleva durante períodos mais secos e quentes.

Figura 25 - Comparativo entre os valores de TBS nas duas células-teste em relação aos índices de temperatura e umidade relativa do ar externo no $2 \%$ período

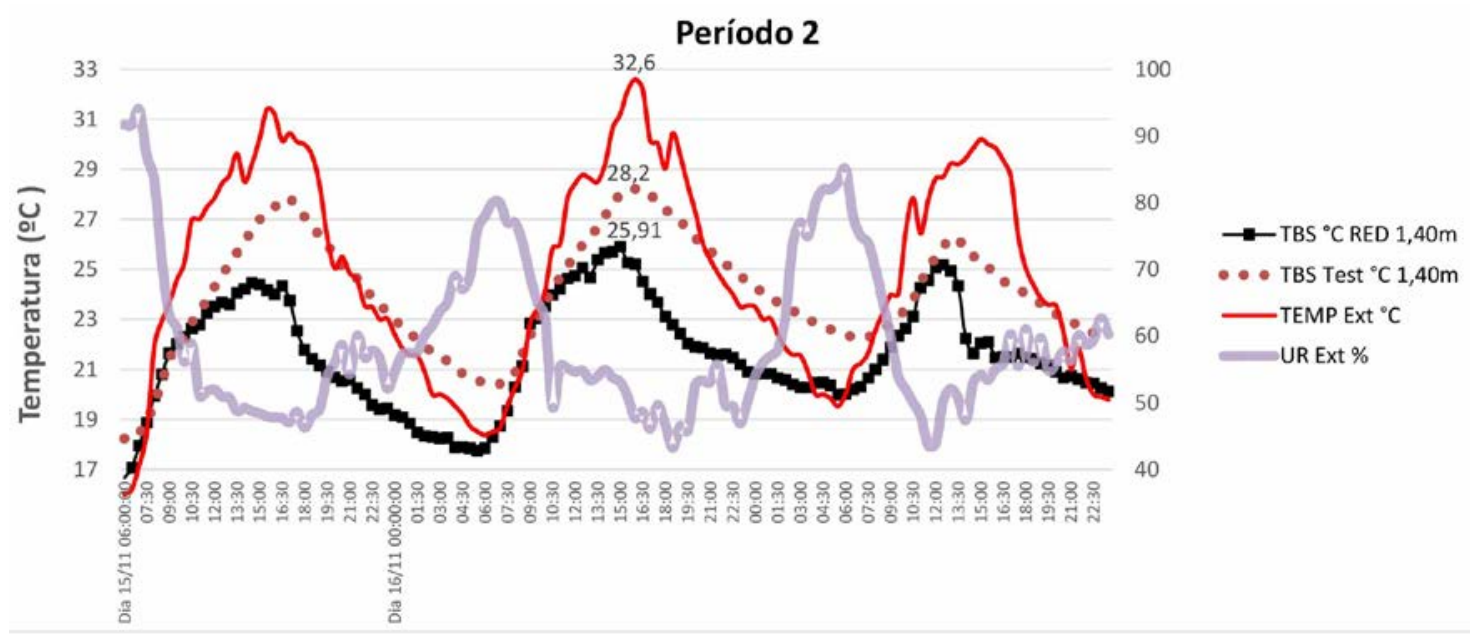

Figura 26 - Gradiente vertical de TBS na célula-teste com RED em três alturas no 2 o período

Gradiente de Temperatura - Célula RED - Período 2

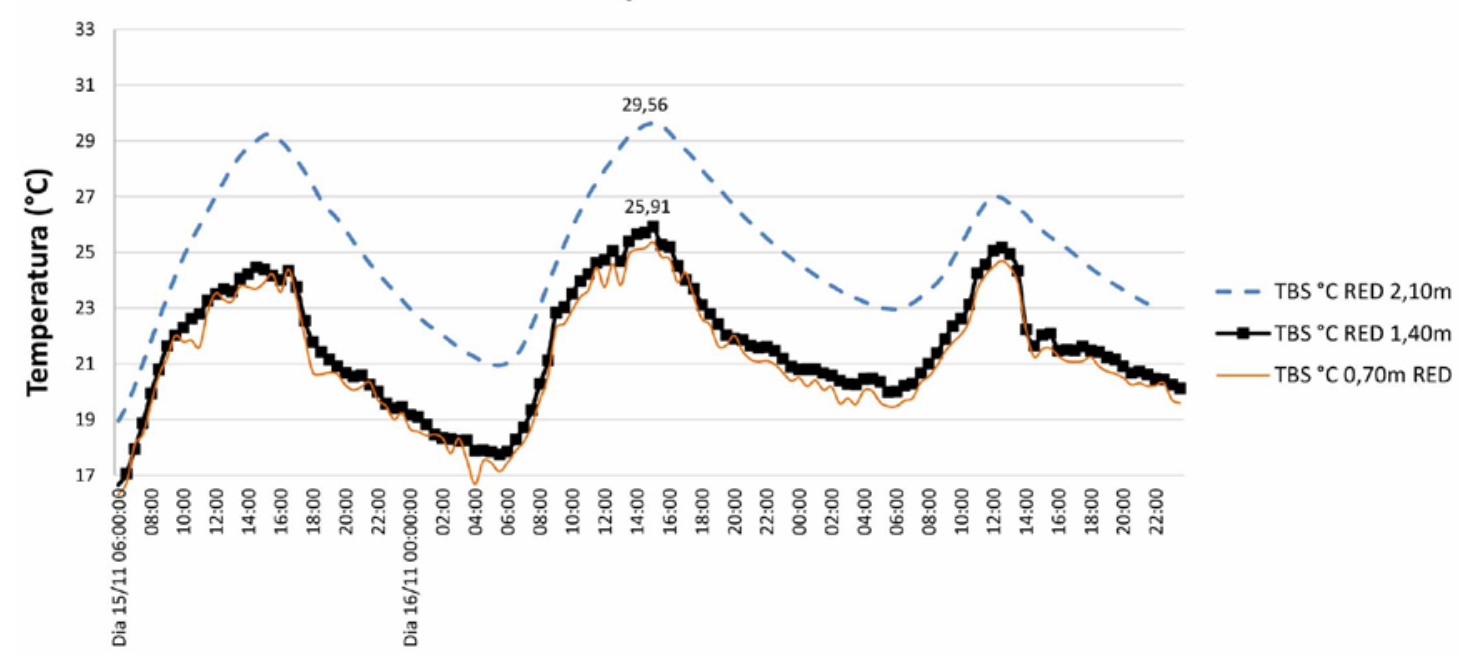


Figura 27 - Gradiente horizontal de TBS na célula-teste com RED em comparação com a temperatura externa do ar no $2 \%$ período

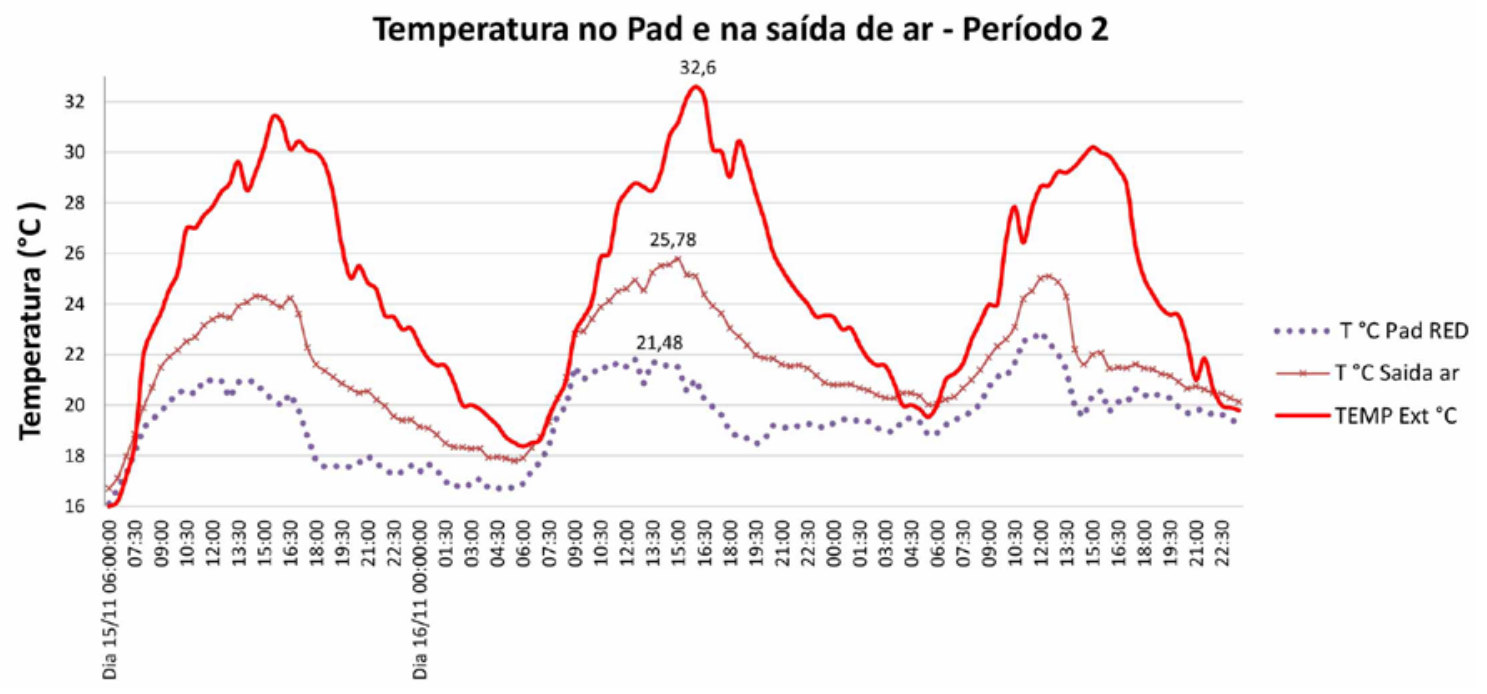

Figura 28 - Variação da amplitude térmica nos dois períodos

Amplitude Térmica Período 1

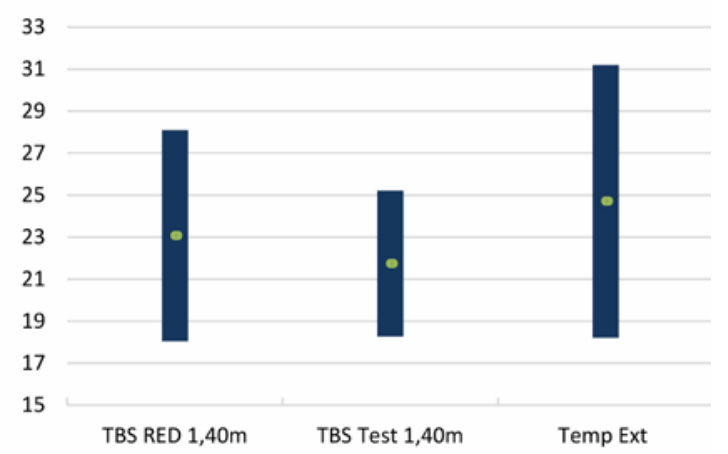

Amplitude Térmica Período 2

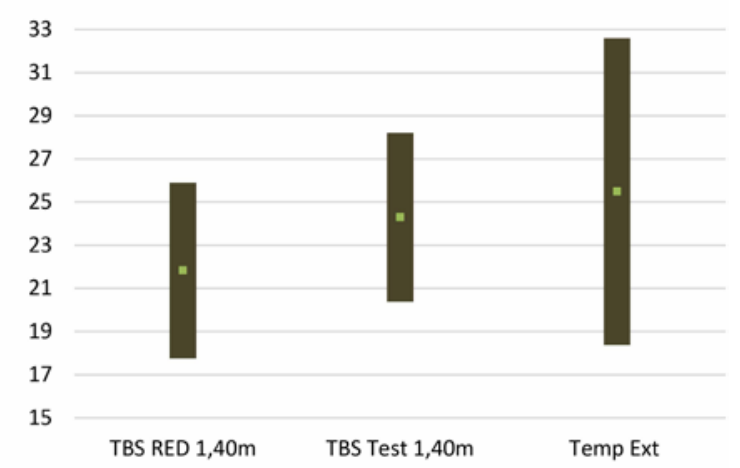

Figura 29 - Gradiente vertical de temperatura nos períodos 1 e 2

Gradiente Vertical Período 1

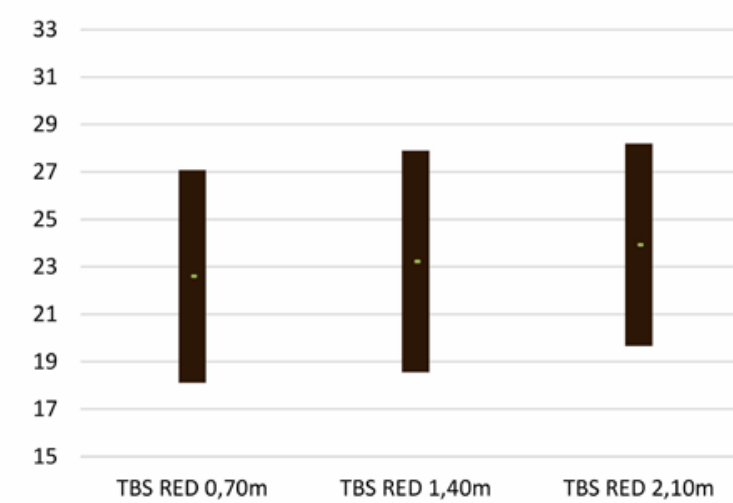

Gradiente Vertical Período 2

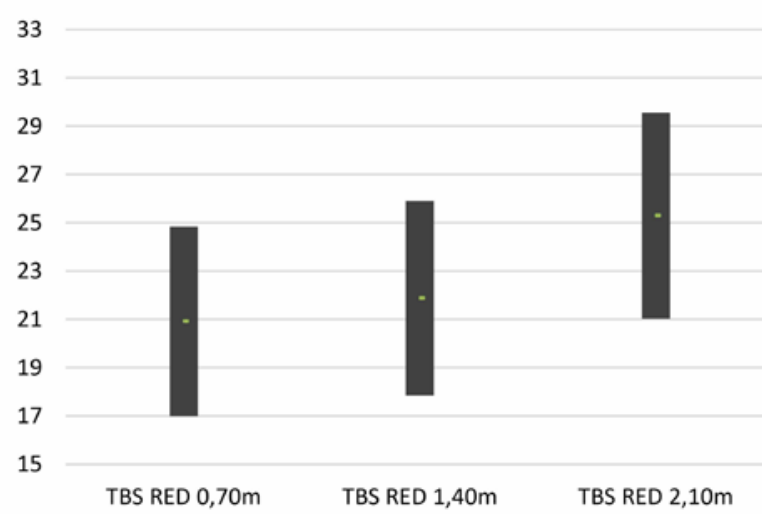




\section{Figura 30 - Gradiente horizontal de temperatura nos períodos 1 e 2}

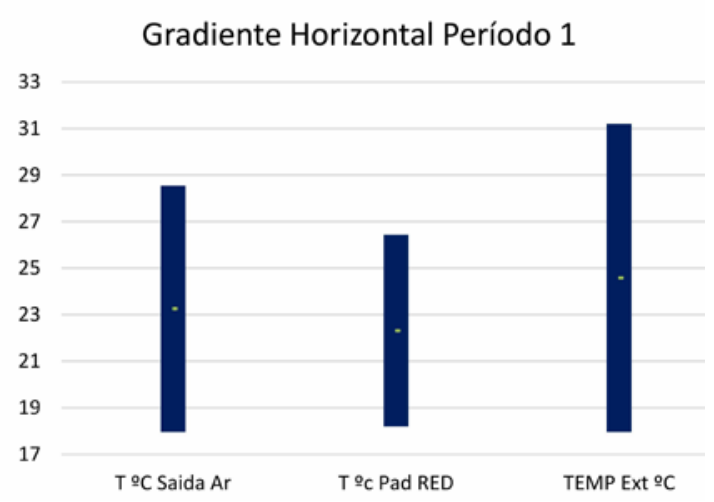

Gradiente Horizontal Período 2

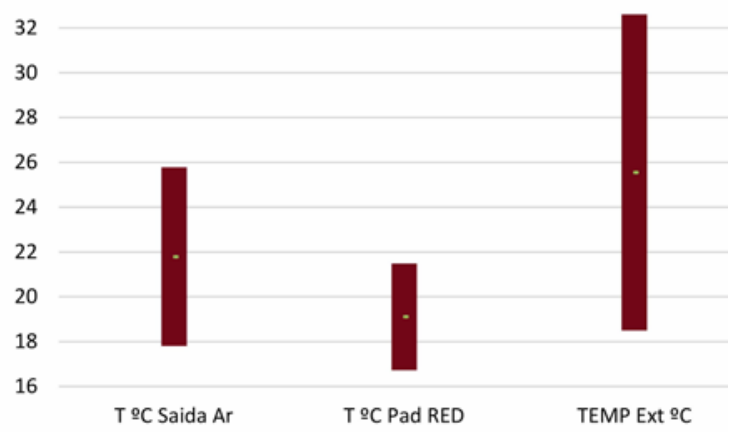

As Tabelas 1 e 2 apresentam as diferenças médias entre as TBS e TBU no interior das células durante os dois períodos em comparação com a média de temperatura externa do ar. Nota-se que a diferença entre a TBS e a TBU externa do ar é de $0,22^{\circ} \mathrm{C}$ no período 1 e de $5,54^{\circ} \mathrm{C}$ no período 2 . Assim, a maior redução média da TBS atingiu $3,25^{\circ} \mathrm{C}$ no período 2 na célula com RED, enquanto no período 1 a redução média foi de apenas 0,78 ${ }^{\circ} \mathrm{C}$.

\section{Consumo de água}

Os principais fatores notados que contribuem para o aumento do consumo de água no processo de resfriamento evaporativo direto são a umidade, a temperatura do ar e a velocidade dos ventiladores do resfriador evaporativo. Devido à falta de um sensor de umidade no aparelho de resfriamento evaporativo utilizado que regule a quantidade de água lançada no ambiente, o ar interno pode saturar caso o aparelho continue funcionando ininterruptamente durante a noite ou em períodos de elevada umidade. As Tabelas 3 e 4 apresentam resumidamente as relações obtidas entre consumo médio de água em litros por hora em função das faixas de temperatura e umidade relativa do ar em duas velocidades diferentes de funcionamento do aparelho resfriador evaporativo, alta e baixa.

Foi possível constatar que o consumo de água variou de 1,05 l/h, registrado nas condições mais úmidas da atmosfera, a $3,35 \mathrm{l} / \mathrm{h}$, quando a umidade relativa do ar externo atingiu $60 \%$, com a temperatura por volta dos $30{ }^{\circ} \mathrm{C}$, durante a velocidade alta de funcionamento dos ventiladores.

\section{Correlação entre variáveis}

Os resultados evidenciam que as condições de umidade do ar externo decorrentes da atuação das massas de ar atmosféricos influenciam decisivamente na variação de temperatura do ar interno das células-teste. Para garantir a efetividade de funcionamento do RED, a evaporação deve ser favorecida pela ventilação cruzada internamente, caso contrário o ambiente interno se torna vulnerável à variabilidade do clima local. Sendo assim, foi elaborada a Figura 31, de dispersão com o coeficiente de correlação de Pearson, para apresentar o grau de influência da umidade relativa do ar externo na variação de TBS do ar interno de uma célula com RED. O coeficiente $\mathrm{R}^{2}=0,7689$ evidencia uma relação inversamente proporcional e moderadamente forte entre as variáveis analisadas. Esse fato corrobora a afirmação de Watt e Brown (1997) de que, quanto menor a umidade do ar, maior a eficiência de um sistema de RED.

Entre os estudos que têm sido desenvolvidos com sistemas de RED destaca-se o de Boukhanouf et al. (2014), que relata a eficiência de um sistema testado em laboratório utilizando painel resfriador de cerâmica porosa preenchida com água. $\mathrm{O}$ experimento demonstrou para clima quente e seco redução de $10{ }^{\circ} \mathrm{C}$ na temperatura do ar interno a partir das condições de entrada de temperatura do ar a $35^{\circ} \mathrm{C}$ e de umidade relativa de $35 \%$.

A eficiência de um sistema passivo de REI é relatada por Krüger et al. (2016) utilizando a água como elemento complementar ao aumento da resistência térmica na cobertura de células-teste. Tais resultados demonstram o potencial da técnica na melhoria das condições térmicas de ambientes situados em regiões subtropicais, como Curitiba, PR, para períodos quentes, como o final da primavera e o início de verão. Estudos de Gonzalez e Krüger (2013), realizados em Florianópolis, SC, e de González-Garcia (2010) em Maracaibo, na Venezuela, também relatam a eficiência do uso da água tanto para aumentar o isolamento térmico de edificações como para resfriar superfícies expostas aos ganhos térmicos decorrentes da radiação solar. Entre os efeitos 
propiciados tanto pelos sistemas de REI quanto de RED está a minimização da amplitude térmica diária em ambientes internos.

Em relação ao consumo de água propiciado por sistemas de RED, Sahai et al. (2012) e Guan, Bennett e Bell (2015) estimam que pode variar entre 200 l/morador/dia e 650 l/morador/dia, considerando temperaturas acima de $26{ }^{\circ} \mathrm{C}$ para baixos índices de umidade relativa. Embora o estudo desenvolvido nas células-teste no campo experimental do CRHEA-USP aponte para um consumo máximo de 3,35 l/h de água, seria importante desenvolver estudos em ambientes residenciais com ocupação humana em diversos tipos climáticos brasileiros ao longo do ano, já que o estudo considerou apenas um ambiente de aproximadamente $16 \mathrm{~m}^{3}$ sem ocupação humana.

Estudos experimentais em ambientes em escala real facilitam o controle, a observação e o registro das variáveis sob a influência da dinâmica climática local. Tais estudos, além de enriquecerem a literatura científica, também podem corroborar informações técnicas para os diversos modelos matemáticos de interpretação dos fenômenos físicos e para os procedimentos de simulação de efeitos da aplicação de técnicas passivas e híbridas de condicionamento térmico das edificações. Cardoso, Claro Neto eVecchia (2012) e Cardoso e Vecchia (2014) relatam que episódios climáticos devem ser caracterizados por sua repercussão no espaço construído e, em particular, na envoltória do edifício, definindo sua avaliação térmica e de consumo energético para resfriamento ou aquecimento.

Tabela 1 - Diferença média entre TBS e TBU no período 1

\begin{tabular}{c|c|c|c|c|c}
\hline $\begin{array}{c}\text { TBS } \\
\text { Ext }\end{array}{ }^{\circ} \mathbf{C}$ & $\begin{array}{c}\text { UR Ext } \\
\%\end{array}$ & $\begin{array}{c}\text { TBU Ext }{ }^{\circ} \mathbf{C} \\
\text { Período 1 }\end{array}$ & $\begin{array}{c}\text { Diferença entre TBS } \\
\text { e TBU Ext Período 1 } \\
\text { To }\end{array}$ & $\begin{array}{c}\text { Redução da TBS } \\
\text { Período 1 Cel. } \\
\text { RED }{ }^{\circ} \mathbf{C}\end{array}$ & $\begin{array}{c}\text { Redução da TBS } \\
\text { Período 1 Cel. } \\
\text { Testem }{ }^{\circ} \mathbf{C}\end{array}$ \\
\hline 23,22 & 86,96 & 23,00 & 0,22 & 0,78 & 1,88 \\
\hline
\end{tabular}

Tabela 2 - Diferença média entre TBS e TBU no período 2

\begin{tabular}{c|c|c|c|c|c}
\hline $\begin{array}{c}\text { TBS } \\
\text { Ext }\end{array}{ }^{\circ} \mathbf{C}$ & $\begin{array}{c}\text { UR Ext } \\
\%\end{array}$ & $\begin{array}{c}\text { TBU Ext }^{\circ} \mathbf{C} \\
\text { Período 2 }\end{array}$ & $\begin{array}{c}\text { Diferença entre } \\
\text { TBS e TBU Ext } \\
\text { Período 2 }{ }^{\circ} \mathbf{C}\end{array}$ & $\begin{array}{c}\text { Redução da TBS } \\
\text { Período 2 Cel. } \\
\text { RED }{ }^{\circ} \mathbf{C}\end{array}$ & $\begin{array}{c}\text { Redução da TBS } \\
\text { Período 2 Cel. } \\
\text { Testem }{ }^{\circ} \mathbf{C}\end{array}$ \\
\hline 24,84 & 59,28 & 19,30 & 5,54 & 3,25 & 2,04 \\
\hline
\end{tabular}

Tabela 3 - Variação de consumo de água em função da umidade, da temperatura e da velocidade baixa de funcionamento do motor do RED

\begin{tabular}{c|c|c|c}
\hline \multicolumn{4}{|c}{ Velocidade baixa $=\mathbf{0 , 1} \mathbf{~ m} / \mathbf{s}$} \\
\hline \multirow{2}{*}{$\begin{array}{c}\text { Faixas de } \\
\text { UR\% }\end{array}$} & \multicolumn{2}{|c}{ Faixas de temperatura do ar na célula testemunho } \\
\cline { 2 - 4 } & $\mathbf{2 0} \mathbf{C}$ & $\mathbf{2 5}{ }^{\circ} \mathbf{C}$ & $\mathbf{3 0}^{\circ} \mathbf{C}$ \\
\hline 70 & & & $2,25 \mathrm{l} / \mathrm{h}$ \\
80 & & $1,45 \mathrm{l} / \mathrm{h}$ & \\
90 & $1,05 \mathrm{l} / \mathrm{h}$ & & \\
\hline
\end{tabular}

Tabela 4 - Variação de consumo de água em função da umidade, da temperatura e da velocidade alta de funcionamento do motor do RED

\begin{tabular}{c|c|c|c}
\hline \multicolumn{4}{c}{ Velocidade alta $=\mathbf{0 , 8} \mathbf{~ m} / \mathbf{s}$} \\
\hline \multirow{2}{*}{$\begin{array}{c}\text { Faixas de } \\
\text { UR\% }\end{array}$} & \multicolumn{2}{|c}{ Faixas de temperatura do ar na célula testemunho } \\
\cline { 2 - 4 } & $\mathbf{2 0}^{\circ} \mathbf{C}$ & $\mathbf{2 5}^{\circ} \mathbf{C}$ & $3{ }^{\circ} \mathbf{C}$ \\
\hline 60 & & & $3,35 \mathrm{l} / \mathrm{h}$ \\
80 & & $2,35 \mathrm{l} / \mathrm{h}$ & \\
100 & $1,55 \mathrm{l} / \mathrm{h}$ & & \\
\hline
\end{tabular}




\section{Figura 31 - Correlação entre umidade relativa externa do ar e TBS interna à célula-teste com RED}

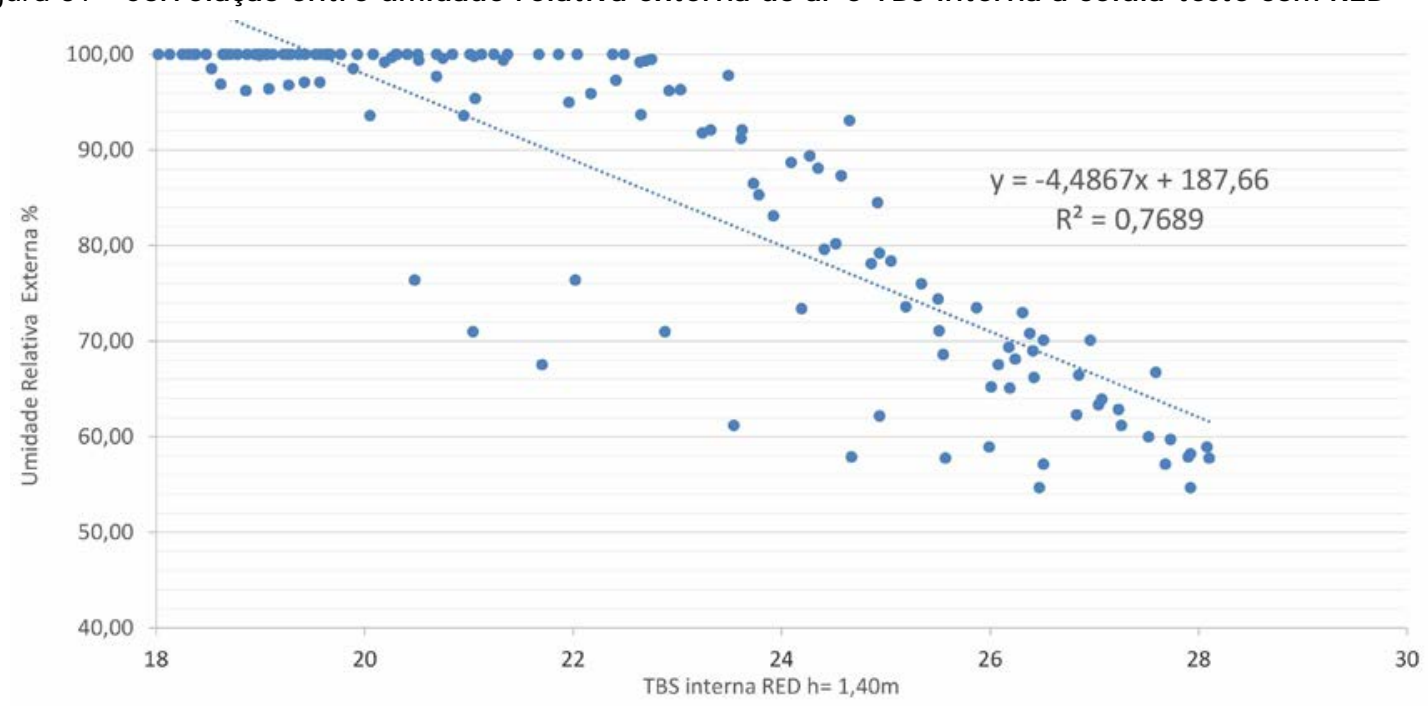

Algumas limitações do uso do RED foram constatadas durante os períodos demasiadamente quentes e úmidos, porém é necessário ressaltar que a técnica pode ser aplicada em ambientes de permanência humana que não necessitem de sistemas de climatização artificial acurada e constante, pois demonstrou ser extremamente dependente das condições climáticas do local de uso. É notório que os recursos de aplicação de condicionadores de ar convencionais são nitidamente maiores que os do resfriamento evaporativo, porém seu consumo energético é demasiadamente elevado, conforme relatam Khandelwal, Talukdar e Jain (2011). Nesse sentido, a redução do consumo energético, a simplicidade de aplicação, a adaptabilidade às diversas condições climáticas, o baixo custo e a facilidade de instalação e operação, relatados por Maurya, Shrivastav e Shrivastava (2014) e Chaudhari et al. (2015), são fatores que devem ser considerados na escolha e na especificação de aparelhos de RED para determinados ambientes. Dispositivos como as torres de resfriamento propostas por Chalfoun (1997), Pearlmutter et al. (1996) e Fathy (1986), as quais, em termos gerais, filtram, umidificam e redirecionam o fluxo natural do ar para o interior da edificação, mostram que o uso do RED pode ser completamente passivo em determinadas épocas do ano, dependendo das características do clima da região.

\section{Conclusão}

As contribuições desta pesquisa estão relacionadas a seu caráter basicamente experimental, o que resultou em um extenso material para futuras discussões sobre o tema. No entanto, cabe ressaltar a necessidade do desenvolvimento de estudos que analisem o consumo energético dos aparelhos RED.

A partir das observações do funcionamento do RED é possível enumerar fatores positivos e negativos que devem ser considerados para sua aplicação. Entre os aspectos positivos destacam-se a eficiência nos períodos quentes e secos, a facilidade de limpeza dos filtros, a renovação do ar interno e a possibilidade de ser aplicado em ambientes externos. Entre os aspectos negativos destacam-se o baixo desempenho em períodos de clima quente e úmido e a vulnerabilidade das características climáticas do local que o sistema impõe ao ambiente interno.

Em relação ao consumo de água no processo de RED é importante frisar que a umidade, a temperatura do ar e a velocidade dos ventiladores do resfriador evaporativo são os fatores de maior influência. É necessário, sobretudo, atenção quanto à qualidade da água usada, pois nem sempre a água fornecida pela rede pública é de boa qualidade, além de haver a possibilidade de acúmulo de fungos tanto no reservatório quanto no pad cooling do aparelho, dados que podem ser observadas em futuras pesquisas.

O método experimental comparativo adotado neste trabalho contribuiu para a compreensão, em linhas gerais, do funcionamento de um sistema de RED, em que a difusão das técnicas de resfriamento evaporativo depende principalmente da formação de parâmetros adequados de sua aplicação a partir da geografia local e da adaptabilidade das edificações. Espera-se que a difusão das técnicas de resfriamento evaporativo abra possibilidades de aprimoramento na concepção de projetos arquitetônicos tanto de edifícios quanto de espaços externos de uso humano. 


\section{Referências}

AMERICAN SOCIETY OF HEATING, REFRIGERATING AND AIR-CONDITIONING ENGINEERS. Chapter 47, Evaporative Air Cooling. ASHRAE Applications Handbook, 1995. Atlanta: American Society of Heating, Refrigerating and Air-conditioning Engineers. New York, NY, 1995.

AMERICAN SOCIETY OF HEATING, REFRIGERATING AND AIR-CONDITIONING ENGINEERS. Psychrometrics - Theory and Practice, ASHRAE Research Project, 1995. Atlanta: American Society of Heating, Refrigerating and Air-conditioning Engineers. New York, NY, 1996.

BOUKHANOUF, R. et al. Investigation of an evaporative cooler for buildings in hot and dry climates. Journal of Clean Energy Technologies, v. 2, n. 3, Jul. 2014.

CAMPBELL SCIENTIFIC. Air temperature and relative humidity sensor. Disponível em: https://www.campbellsci.com.br. Acesso em: 20 mar. 2019b.

CAMPBELL SCIENTIFIC. Datalogger CR10X. Disponível em: https://www.campbellsci.com.br/cr10x. Acesso em: 20 mar. 2019a.

CAMPBELL SCIENTIFIC. Multiplexer AM416. Disponível em: https://www.campbellsci.com.br/am416. Acesso em: 20 mar. 2019c.

CARDOSO, G. T.; CLARO NETO, S.; VECCHIA, F. Rigid foam polyurethane (PU) derived from castor oil (Ricinus communis) for thermal insulation in roof. Frontiers of Architectural Research, v. 1, p. 348-356, 2012.

CARDOSO, G. T.; VECCHIA, F. Thermal behavior of green roofs applied to tropical climate. Jounal of Construction Engineeringv. 1, n. 1, p. 1-7, 2013.

CARDOSO, G. T.; VECCHIA, F. Comparison of thermal performance between test cells with different coverage systems for experimental typical day of heat in Brazilian Southeastern. Frontiers of Architectural Research, v. 3, p. 271-282, 2014.

CENTRO DE PREVISÃO DE TEMPO E ESTUDOS CLIMÁTICOS. CPTEC - INPE Estação do ano: primavera. Disponível em: http://clima1.cptec.inpe.br/estacoes/. Acesso em: 22 jan. 2019.

CENTRO DE RECURSOS HÍDRICOS E ESTUDOS AMBIENTAIS. Dados climatológicos: setembro a dezembro de 2005. Departamento de Hidráulica e Saneamento. Escola de Engenharia de São Carlos. Universidade de São Paulo. São Carlos, 2005.

CENTRO DE RECURSOS HÍDRICOS E ESTUDOS AMBIENTAIS. Mapa localização. Departamento de Hidráulica e Saneamento. Escola de Engenharia de São Carlos. Universidade de São Paulo. São Carlos, 2019. Disponível em: http://www.usp.br/mapas/mapas/pdf/crhea.pdf. Acesso em: 21 jan. 2019.

CHALFOUN, N. D. Implementation of natural down-draft evaporative cooling devices in commercial buildings. University of Arizona, 1997. Disponível em: http://ceac.arizona.edu/sites/default/files/chalfoun__implementation_of_natural_down-draft_evaporative_cooling_devices.pdf . Acesso em: 8 fev. 2019.

CHAUDHARI, B. D. et al. A review on evaporative cooling technology. International Journal of Research in Advent Technology, v. 3, n. 2, Feb. 2015.

DESCHENES, O. Temperature, human health and adaptation: A review of the empirical literature. Energy Economics, v. 46, p. 606-619, 2014.

ECOBRISA. Especificaçõe técnicas: climatizador evaporativo EB-20. Disponível em: https://www.ecobrisa.com.br. Acesso em: 23 mar. 2019.

FATHY, H. Vernacular architecture: principles and examples with references to hot arid climates. Chicago: The University of Chicago Press, 1986.

GIVONI, B. Climate consideration in building \& urban design. New York: John Wiley, 1998.

GIVONI, B. Minimum climatic information needed to predict performance of passive buildings in hot climates. In: CONFERENCE. PASSIVE AND LOW ENERGY ARCHITECTURE, SUSTAINING THE FUTURE: ENERGY-ECOLOGY-ARCHITECTURE, Brisbane, 1999. Proceedings [...] Brisbane, 1999.

GIVONI, B. Passive and low energy cooling of buildings. New York: John Wiley, 1994. 
GONZALEZ, E.; KRÜGER, E. L. Enfriamento evaporativo indirecto: predicción del comportamiento térmico en ciudades brasileñas. In: ENCONTRO NACIONAL, 12.; ENCONTRO LATINO-AMERICANO DE CONFORTO NO AMBIENTE CONSTRUÍDO, 8., Brasília, 2013. Anais... Brasília: ANTAC, 2013.

GONZALEZ-GARCIA, S. Estudio experimental del comportamiento térmico de sistemas pasivos de enfriamiento en clima cálido húmedo. Huelva: Universidad Internacional de Andalucía, Sede Internacional de la Rábida, 2010.

GOOGLE EARTH. [Imagem landsat/Copernicus - Itirapina]. Disponível em: https://www.google.com/earth/. Acesso em: 27 nov. 2018.

GUAN, L.; BENNETT, M.; BELL, J. Evaluating the potential use of direct evaporative cooling in Australia. Energy and Buildings, v. 108, p. 185-194, 2015.

KHANDELWAL, A.; TALUKDAR, P.; JAIN, S. Energy savings in a building using regenerative evaporative cooling. Energy and Buildings, v. 43, p. 581-591, 2011.

KRÜGER, E. L. et al. Avaliação do potencial de resfriamento de um sistema teto-reservatório para condições subtropicais. Ambiente Construído, Porto Alegre, v. 16, n. 3, p. 107-125, jul./set. 2016.

MAURYA, R.; SHRIVASTAV, N.; SHRIVASTAVA, V. Performance and analysis of an evaporative cooling system: a review. International Journal of Scientific \& Engineering Research, v. 5, n. 10, Oct. 2014.

NIMER, E. Climatologia do Brasil. Rio de Janeiro: IBGE, 1979.

OZTURK, H. H. Evaporative cooling efficiency of a foging system for greenhouses. Turkish Journal of Agriculture and Foresty, Ankara, v. 27, n. 1, p. 49-57, Jan. 2003.

PEARLMUTTER, D. et al. Refining the use of evaporation in an experimental down-draft cool tower. Energy and Buildings, Lausanne, v. 23, n. 3, p. 191-197, Mar. 1996.

PROGRAMA NACIONAL DE CONSERVAÇÃO DE ENERGIA ELÉTRICA. Pesquisa de posse de equipamentos e hábitos de uso. Ano-base 2005. Classe comercial - alta tensão, relatório Brasil. Agosto 2008. Disponível em: http://www.procelinfo.com.br/services/procel-

info/Simuladores/DownloadSimulator.asp?DocumentID=\%7B834AF658\%2DA5ED\%2D4574\%2D8D6E\% 2D40720865596C\%7D\&ServiceInstUID=\%7B5E202C83\%2DF05D\%2D4280\%2D9004\%2D3D59B20BE A4F\%7D. Acesso em: 21 jan. 2019

RORIZ M. PSICROM 1.0. Software desenvolvido para cálculos de relações psicrométricas. Universidade Federal de São Carlos, Departamento de Engenharia Civil, Programa de Pós-Graduação em Construção Civil. São Carlos, 2003.

RORIZ, V.; RORIZ, M. Resfriamento evaporativo por aspersão de água sobre telhas de fibrocimento em clima semi-úmido. In: ENCONTRO NACIONAL DE TECNOLOGIA DO AMBIENTE CONSTRUÍDO, 12., Fortaleza, 2008. Anais [...] Fortaleza: ANTAC, 2008.

SANTAMOURIS, M.; KOLOKOTSA, D. Passive cooling dissipation techniques for buildings and other structures: the state of the art. Energy and Buildings, v. 57, p. 57-74, 2013.

SCHIRMER, W. N. et al. A poluição do ar em ambientes internos e a síndrome dos edifícios doentes. Ciência \& Saúde Coletiva, Rio de Janeiro, v. 16, n. 8, ago. 2011.

SECRETARIA DE VIGILÂNCIA EM SAÚDE. MINISTÉRIO DA SAÚDE. Perfil da morbimortalidade por doenças respiratórias crônicas no Brasil, 2003 a 2013. Boletim Epidemiológico, v. 47, n. 19, 2016.

TORREIRA, R. P. Elementos básicos de ar condicionado. São Paulo: Hemus, 1976.

VECCHIA, F. A. S. Clima e ambiente construído: a abordagem dinâmica aplicada ao conforto humano. São Paulo, 1997. 316 f. Tese (Doutorado) - Faculdade de Filosofia, Letras e Ciências Humanas, Universidade de São Paulo, São Paulo, 1997.

WATT, J. R.; BROWN, W. K. Evaporative air conditioning handbook. 3. ed. Lilburn: Fairmont, 1997. WORLD HEALTH ORGANIZATION. Guidelines for indoor air quality: selected pollutants. 2015. Disponível em: http://www.euro.who.int/_data/assets/pdf_file/0009/128169/e94535.pdf?ua=1. Acesso em: 21 jan. 2019. 
YAO-DONG, D. et al. Impacts of climate change on human health and adaptation strategies in South China. Advances in Climate Change Research, v. 4, n. 4, p. 208-214, 2013.

\section{Agradecimento}

Os autores agradecem à Coordenação de Aperfeiçoamento de Pessoal de Nível Superior (Capes) e ao Conselho Nacional de Desenvolvimento Científico e Tecnológico (CNPq) pelo apoio a este trabalho.

\section{Erico Masiero}

Departamento de Engenharia Civil, Programa de Pós Graduação em Engenharia Urbana | Universidade Federal de São Carlos | Rodovia Washington Luis Km 235 | Caixa Postal 676 | CEP 13565-905 | Tel.: (16) 3306-6442 | E-mail: ericomasiero@yahoo.com.br

\section{Djanny Klismara Oliveira}

Programa de Pós Graduação em Engenharia Urbana | Universidade Federal de São Carlos | E-mail: djanny215@gmail.com

\section{Orlando pereira da Costa}

Programa de Pós Graduação em Engenharia Urbana | Universidade Federal de São Carlos | E-mail: arquitetoorlandocosta@gmail.com

\section{Francisco Arthur da Silva Vecchia}

Pós-Graduação em Ciências da Engenharia Ambiental | Escola de Engenharia de São Carlos | Universidade de São Paulo | Av. Trabalhador São-carlense, 400, Parque Arnold Schimidt | São Carlos - SP - Brasil | CEP 13566-590| E-mail: fvecchia@sc.usp.br

\section{Ambiente Construído}

Revista da Associação Nacional de Tecnologia do Ambiente Construído

Av. Osvaldo Aranha, 99 - 3o andar, Centro

Porto Alegre - RS - Brasil

$$
\text { CEP 90035-190 }
$$

Telefone: +55 (51) 3308-4084

Fax: +55 (51) 3308-4054

www. seer. ufrgs. br/ ambienteconstruido

E-mail: ambienteconstruido@ufrgs.br 